\title{
AUTORA INVITADA
}

\section{LAS FACETAS DEL DIALOGISMO EN UNA DISCUSIÓN CORRIENTE ${ }^{1}$}

\author{
ANNE SALAZAR ORVIG*
}

\section{EL DIALOGISMO, UNA NOCIÓN POLIFACÉTICA}

Al sumergirse ${ }^{2}$ en la lectura de Bajtín, uno se da cuenta de que el dialogismo constituye una noción compleja y multiforme. Diversos autores han criticado su carácter demasiado potente y plurívoco, tal como se puede leer, por ejemplo, al principio del artículo "Dialogisme" del Dictionnaire d'analyse du discours: "el término se ha cargado de una pluralidad de sentidos problemática" no solamente como plantea aquí Todorov (1981, p. 95) a lo largo de los escritos del Círculo de Bajtín, sino igualmente de la manera "como lo han ido comprendiendo y trabajando diferentes autores" (Moirand, 2002, p. 175).

Si nos referimos a Bajtín ${ }^{3}$ esta noción remite, al menos, a dos dimensiones complementarias: de una parte, a la primacía del diálogo o de la interacción verbal (François, 1984) en el lenguaje y de manera más general en la naturaleza humana (Marková 2003b) ${ }^{4}$; de otra parte, en una tradición más lingüística, a la dimensión constitutiva del lenguaje que corresponde al hecho de que todo discurso depende de los que le preceden y proyecta los discursos posteriores, constituyéndose de esta manera como "un eslabón en la cadena de la comunicación discursiva" (Batjín, 1982, p. 265). Esto implica que no existe discurso que pueda ser concebido, producido o elaborado por una instancia ajena a la circulación de los discursos.

Esta dependencia ${ }^{5}$ involucra diferentes modos de relación con los discursos anteriores o futuros, reales o virtuales, tales como la repetición-modifi- cación (François, 1984), el "diálogo implícito" con otros discursos (Bres, 1998), o, también, la intertextualidad (Todorov, 1981; Moirand, 2002). Esto implica, a su vez, que todo discurso es constitutivamente heterogéneo (Authier-Revuz, 1995), lo que ha sido descrito en términos de polifonía (Ducrot, 1980 y 1984) o de desdoblamiento enunciativo (Bres, 1998 y 1999; Bres y Vérine, 2002; Haillet, 1998; Vion, 1998a, 1998b y 2001).

\footnotetext{
${ }^{1}$ Este artículo apareció en francés en las Actas del Coloquio sobre Bajtín de la Universidad Cergy-Pontoise, cuyos organizadores amablemente han autorizado su traducción y primera publicación en lengua española. Traducción de Rosa Delia Morales Villota. Investigadora del Grupo Lenguaje, Cultura e Identidad, Universidad Distrital Francisco José de Caldas.

* PhD en lingüística, Universidad de La Sorbona. Profesora de la Universidad de París 3-Sorbonne Nouvelle \& Leaple (CNRS-París V). salazar.orvig@wanadoo.fr

${ }^{2}$ Este trabajo le debe mucho a la colaboración de Michèle Grossen de la Universidad de Lausana, con quien llevamos a cabo una investigación sobre los focus groups (Salazar Orvig y Grossen, 2004a y 2004b).

${ }^{3}$ Pero él mismo se inscribe en una tradición filosófica neo-kantiana (Buber, Cohen, Rosentock, Rozenzweig, entre otros) que se fundamenta en el principio dialógico (Todorov, 1981; Marková, 2003b; Linell, 1998).

${ }^{4}$ Por otra parte, Marková o Linell distinguen dialogicalidad y dialogismo: la primera hace referencia a la dimensión constitutiva del hecho humano ("Dialogicality is the fundamental capacity of the human mind to conceive, create and comunicate about social realities in terms of the Alter" (Marková, 2003, p. 85), mientras el segundo correspondería más a su expresión discursiva o lingüística.

${ }^{5}$ Esta dimensión ha sido igualmente planteada por autores como Foucault (1969) y Pêcheux (1975) (ver Authier-Revuz, 1995; Bres, 1998) cuya influencia en Francia ha marcado profundamente la reflexión sobre el tema del dialogismo.
}

ARTículo RECIBIDO 30 DE MAYO DE 2004. ACEPTADO 13 DE JUNIO DE 2004. 
Frente a esta complejidad, los diferentes investigadores, sin dejar de subrayar el carácter fundamental del dialogismo, privilegian ciertos aspectos: las relaciones con discursos anteriores (Moirand), las expresiones de la heterogeneidad constitutiva de los discursos (Authier-Revuz), las marcas lingüísticas, índices del "diálogo implícito" (Bres, Haillet, Ducrot) además de la pluralidad enunciativa (Vion). Estas opciones constituyen diversas vías de acercamiento al discurso, lo que muestra, a la vez, su potencialidad y su pertinencia lingüística. Tomaré como punto de partida estas propuestas para plantear una pregunta complementaria: ¿cómo interviene este principio fundamental en la dinámica de un discurso o en un diálogo común y corriente? ¿Qué formas toma? ¿Qué facetas son movilizadas? Antes de intentar responder a estas preguntas quisiera detenerme en la presentación de las diferentes facetas del dialogismo tal como aparecen en los textos de Bajtín.

\section{LAS FACETAS DEL DIALOGISMO EN LOS TEXTOS DE BAJTÍN}

Si el concepto de dialogismo parece polifacético, se debe, en primer lugar, al autodialogismo interno de los textos de Bajtín, a los replanteamientos y retornos que se constatan en textoș como Marxis-

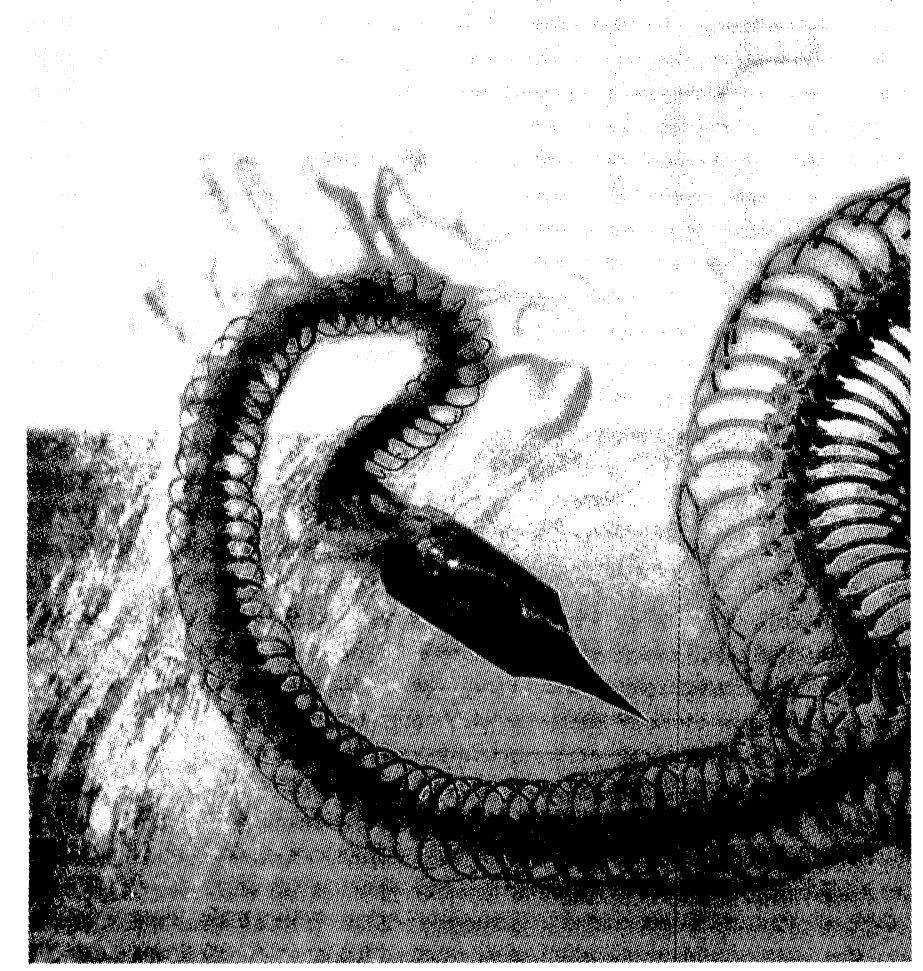

mo y filosofía del lenguaje, Teoría y Estética de la novela y Estética de la creación verbal, o inclusive Problemas de la poética de Dostoïevsky. De la lectura de estos textos sobresale que la noción de dialogismo no se limita a la constatación de la relación de un enunciado con otros enunciados pasados o futuros. Esta afirmación se inscribe ante todo en una epistemología fundada sobre la idea de que el diálogo es la realidad fundamental del lenguaje y de la experiencia humana.

\subsection{El dialogismo como epistemología}

Como lo han mostrado otros autores (Todorov, 1981; Marková, 2003b), Bajtín (1982) asume una concepción dialógica de las ciencias humanas, del hecho humano, y, en consecuencia, de la lengua, del lenguaje y de la lingüística. Opone las ciencias humanas a las ciencias de la naturaleza enfatizando en el hecho de que, al contrario de las "cosas mudas" que caracterizan al objeto de las ciencias de la naturaleza, las ciencias humanas tienen que ver con productos humanos $\mathrm{y}$, por lo tanto, con objetos cargados de sentido. Debido a esto se instala una relación dialógica entre el investigador y su objeto. Se trata de: "Pensamiento acerca del pensamiento, del discurso acerca del discurso, del texto acerca de los textos" (Batjín, 1982, p. 294).

Esta relación entre dos conciencias es una relación de respuesta y, por lo tanto, portadora de diferencia, de no coincidencia. Sólo una posición monológica pretende tener la última palabra; el dialogismo, al contrario, supone el reconocimiento de una posición fundamentalmente interpretativa.

El dialogismo es igualmente constitutivo de todo hecho humano y, por lo tanto, del sujeto. La relación con el mundo y la relación consigo mismo están mediatizadas por el discurso del otro. Particularmente, la relación de los hablantes con su lengua, pasa por la relación establecida con las palabras ajenas: "Por eso la experiencia discursiva de cada persona se forma y se desarrolla en una constante interacción con los enunciados individuales y ajenos. Esta experiencia puede ser caracterizada, en cierta medida, como procesos de asimilación (más o menos creativa) de palabras ajenas (y no de palabras de la lengua)" (Batjín, 1982, p. 279).

Resulta de esto, una concepción radicalmente diferente de las formas de la lengua y, por lo tanto, del trabajo lingüístico. Conocemos la crítica hecha en el texto firmado por Voloshinov al objetivismo abstracto y al subjetivismo idealista. Al primero, 
el autor reprocha el tratamiento de la lengua como. una lengua muerta, $y$, al segundo, el hecho de ignorar la realidad-social del lenguaje. De esta manera, recuerda que toda enunciación es la respuesta a algo, y que las palabras y enunciados son "el producto de la interacción del hablante y el oyente" (Batjín y Voloshinov, 1992, p. 121).

Bajtín considera que la lingüística o la gramática tradicional son incapaces de dar cuenta de los enunciados y su inscripción en el intercambio verbal. Por lo tanto, propone una concepción nueva de la lingüística, o más bien una nueva disciplina, la trans o metalingüística (1985) cuyo punto de partida no son las unidades mínimas ni el sistema de la lengua, sino las formas y tipo de interacción verbal, para llegar luego, a las formas de las lenguas pasando por el estudio de las formas de enunciación, de los actos de habla, en relación con la interacción. De aquí surge, por otra parte, la importancia de la noción de género que constituye justamente el elemento mediador entre las enunciaciones efectivas y las abstracciones lingüísticas. Este contexto teórico constituye el marco donde se debe reflexionar sobre el dialogismo de los enunciados, es decir, a partir de su inscripción en los discursos, en los diálogos y en las actividades comunicativas.

\subsection{El diallogismo de los enunciados}

El dialogismo de los enunciados presenta, también, varias facetas que Bajtín subraya de manera diferente según el texto.

Tomemos como punto de partida la constatación de que el enunciado (o el discurso) se inscribe en una corriente ininterrumpida de discursos y es un eslabón de la cadena del intercambio verbal. Esto constituye una primera faceta de este dialogismo de los enunciados. Pero, al mismo tiempo, Bajtín insiste en que no se trata únicamente de una relación de contigüidad o de contextualización, sino de un hecho constitutivo. El discurso se orienta de dos formas: "En realidad, la palabra representa un acto bilateral. Se determina en la misma medida por aquel a quien pertenece y por aquel a quien está destinada" (Batjín y Voloshinov, 1992).

Por lo tanto, constituye "un puente tendido" entre los interlocutores. Esta inscripción en una cadena a largo plazo, y en un intercambio efectivo tiene efectos sobre la composición, es decir, sobre la estructuración y la forma del enunciado. De esta manera, en todo enunciado resuenan los ecos, los armónicos de otros discursos, de las palabras ajenas (1982).

A su vez, estos armónicos del discurso del otro introducen heterogeneidad en los enunciados. Es lo que Bajtín denomina "plurilingüismo", "plurivocalidad", o "heteroglosia", constitutivos de la polifonía en la novela.

Más allá de esta resonancia, Bajtín recuerda la importancia de la interdependencia de los enunciados: "Los enunciados no son indiferentes unos a otros ni son autosuficientes, sino que 'saben' uno del otro y se reflejan mutuamente. Estos reflejos recíprocos son los que determinan el carácter del enunciado" (Batjín, 1982, p. 281).

Esta interdependencia se refleja también en el conjunto de movimientos que corresponden a la anticipación de la comprensión responsiva.

"Toda palabra está orientada hacia una respuesta y no puede evitar la influencia profunda de la palabra-réplica prevista" (Batjín, 1989, p. 97).

Esta doble orientación es constitutiva de aquello que Bajtín llama dialogización interior, la cual corresponde a un diálogo no desplegado entre sus instancias, a una tensión entre las palabras propias y las palabras ajenas en el seno mismo del enunciado: "En casi todo enunciado tiene lugar una interacción tensa, una lucha entre la palabra propia y la ajena, un proceso de delimitación o de esclarecimiento dialogístico recíproco" (Batjín, 1989, pp. 170-171).

Resulta, por lo tanto, que en todo enunciado se manifiesta una pluralidad de voces o de enunciaciones y se pone en escena este diálogo interno.

Es importante, sin embargo, recalcar que esta dialogización interior concierne tanto a los discursos monologales ${ }^{6}$ que son el objeto privilegiado en los estudios actuales, como a los enunciados en el diálogo efectivo:

Esta doble vida tiene también la réplica en todo diálogo real: está estructurada y se entiende en el contexto completo del diálogo, compuesto de enunciados propios (desde el punto de vista del hablante), y de enunciados ajenos (del

\footnotetext{
${ }^{6}$ Para retomar la distinción de gran utilidad introducida por Roulet et al. (1985) entre dialogal/dialógico y monologal/monológico.
} 
interlocutor). La réplica no puede ser extraída de ese contexto mixto de palabras propias y ajenas sin perder el sentido y el tono. Es la parte orgánica de un conjunto plurilingüe. (Batjín, 1989, p. 101)

También el dialogismo puede corresponder a la mirada que el sujeto proyecta sobre su propia producción discursiva. Aunque es rara vez mencionada por Bajtín (Bres y Vérine, 2002), esta posibilidad es expresada claramente:

Finalmente, las relaciones dialógicas son igualmente posibles con respecto al propio enunciado de uno, en su totalidad, con respecto a sus partes aisladas, y con respecto a la palabra aislada del enunciado, en el caso en que nos separemos de alguna manera de ellos, hablemos con cierta reserva interna, tomemos alguna distancia respecto a ellos o desdoblemos la autoría (Batjín, 1986, p. 257).

Por lo tanto, como ha sido mostrado en este corto recorrido, el dialogismo no podría ser reducido a algunos aspectos de la relación entre un

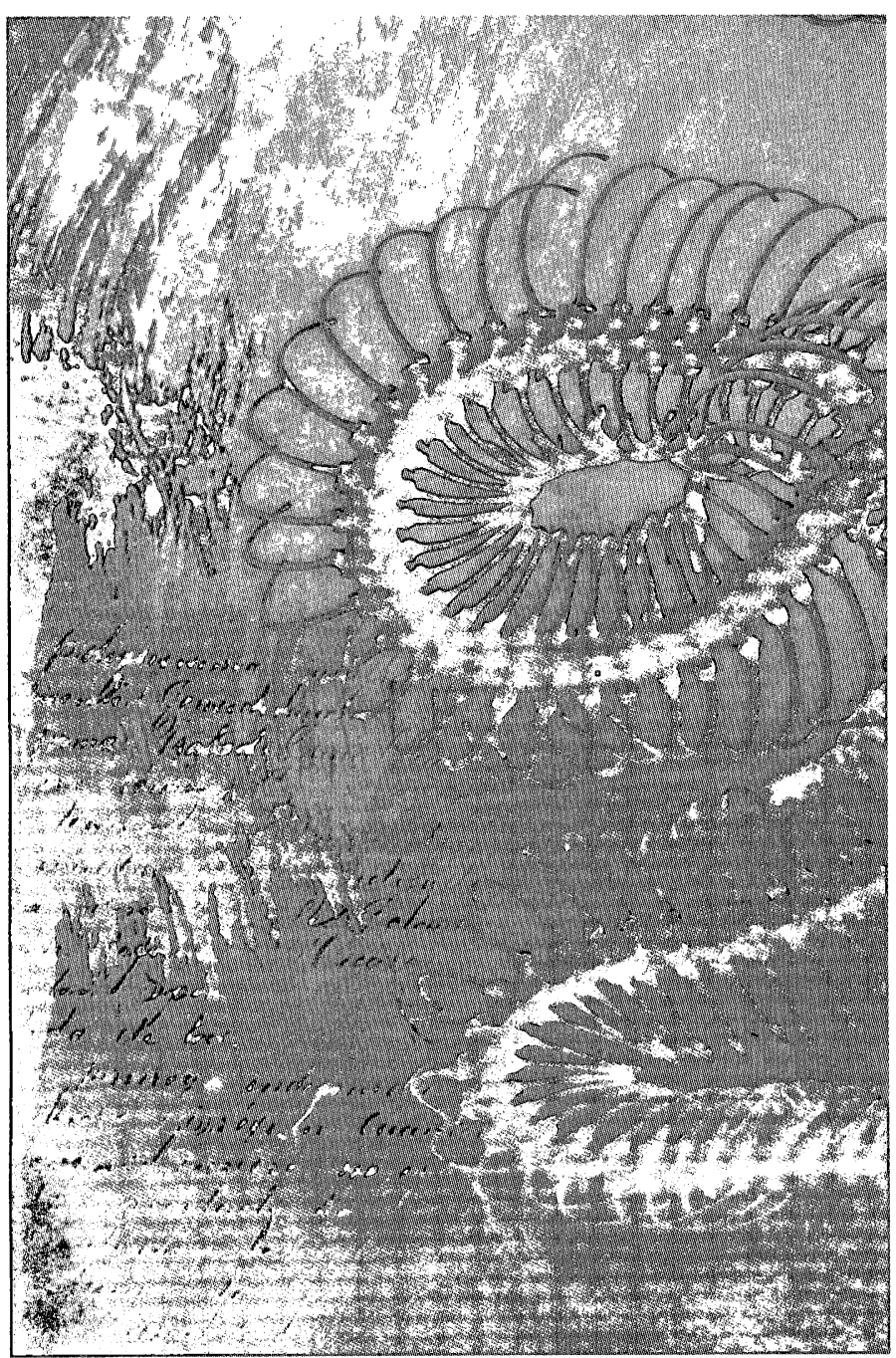

enunciado y su contexto: abarca a la vez, las relaciones externas e internas del enunciado y se involucra en los diferentes niveles de la constitución del discurso.

\section{EL DIALOGISMO EN EL DIÁLOGO}

A partir de lo anterior, el problema radica en dar cuenta de la forma como el dialogismo se manifiesta en el diálogo efectivo y, por consecuencia, en el discurso oral, en los intercambios verbales cotidianos. Este objetivo podría parecer un poco trivial en la medida en que puede decirse que, por definición, el diálogo está marcado por el dialogismo. Sin embargo, esta dimensión no ha sido realmente estudiada en sí; los investigadores se han interesado con mayor insistencia en la estructura del intercambio y en la dinámica de los encadenamientos, aquello que Roulet et al. (1985) llaman lo dialogal, dejando a un lado su aspecto dialógico.

Se trata pues, más bien, de poner en evidencia los mecanismos que subyacen a la constitución de los discursos y, por lo tanto, in fine también a la dimensión monologal... Esto supone a su vez esbozar una reflexión sobre el fundamento dialógico de los movimientos discursivos y de los marcadores lingüísticos que se les asocian.

\subsection{El corpus}

El corpus seleccionado para el presente artículo está constituido por un conjunto de discusiones recogidas con el método de los focus groups (grupos focalizados) (Marková, 2003a) ${ }^{7}$. Los grupos focalizados son grupos de discusión reunidos por un animador alrededor de una problemática dada. En nuestro caso, hemos explorado las representaciones ligadas al secreto médico. Se leyó a grupos de 3 a 5 estudiantes (de lingüística o psicología, de París o de Lausana), una serie de viñetas que planteaban un dilema sobre el cual debían pronunciarse: ya sea respetar el secreto médico y proteger al individuo, o no respetarlo y proteger al grupo, a la pareja, a los demás... Aquí presento dos viñetas sobre las cuales se basarán mis ejemplos:

\footnotetext{
${ }^{7}$ Corpus reunido en el contexto de una investigación llevada a cabo con M. Grossen (Salazar y Grossen, 2004a y 2004b). Esta investigación se inscribe en las actividades de un grupo de trabajo internacional coordinado por I. Marková (Universidad de Stirling, LEPS, MSH) y que se interesa en las representaciones sociales y, en particular, en el método de los focus groups y que ha dado lugar a un número del Bulletin de Psychologie, publicado en el 2004, dirigido por I. Marková y B. Orfali.
} 


\section{Vineta contrato}

Usted tiene una formación básica en Medicina y es jefe del departamento de salud y de acción social del cantón Vaud ${ }^{8}$. Usted encuentra en su escritorio una carta firmada por varios directores de hospitales que le piden la autorización para exigir pruebas de VIH para el contrato de personal. Como responsable del departamento de salud, idebería usted otorgarles esta autorización?

\section{Vineta pareja}

Juan y Paulina están casados desde hace tiempo. Desde hace varios años, Paulina ha tenido regularmente aventuras extraconyugales en las cuales sólo se ha protegido ocasionalmente. Después de un examen de VIH que pidió a su médico comprueba que es seropositiva. Sin embargo, no se lo ha dicho a su esposo. Resulta que su médico también es médico de Juan. Él conoce a la pareja desde hace mucho tiempo y ha establecido una relación de confianza con cada uno de ellos. ¿Deberia este médico decirle a Juan que su esposa es seropositiva?

Estas viñetas dan lugar a toma de posiciones algunas veces convergentes, en otras ocasiones opuestas, en todo caso variables según el contenido de ellas. Son evocados diversos argumentos, cuyo análisis no presentaremos aquí: argumentos legales, de sentido común, personales, emocionales. El ejemplo 1 nos permite dar una mirada al contenido de los debates. Se trata del comienzo de la respuesta a la viñeta pareja.

\section{(1) ILAU1A, Pareja}

Fin de la lectura de la viñeta: ¿Debería este médico decirle a Juan que su esposa es seropositiva?

\section{ANA 30 -pues yo pienso que sí, < risita> \\ MON 28 -yo también pienso así < risa>}

ANA 31 -porque hay ya- la confianza entre la pareja ya no existe, porque bueno pues si desde hace años ella tiene relaciones extraconyugales, entonces pienso que un tercero debe intervenir, en este caso.

$$
\begin{aligned}
& \text { JOE } 48 \quad \text {-yo digo SÍ PERO, + } \\
& <\text { risa general> }
\end{aligned}
$$

JOE -SÍ PERO < risa de los demás>, porque ya cuando tú dices que la relación de confianza está rota, sí y no, + en el sentido que eres tú la que juzgas el hecho de que la relación de confianza esté rota $\S$ pero yo pienso $\S$

ANA $32-\S$ pero si ella no le dice $\S$ porque $\S\{x x x\} \S$

JOE 49 — $\$$ PERO SI § pero es, es, es creo que pienso también, también debe llevársela a que en algún momento lo diga, no creo que - no creo que tú puedas decir \# simplemente así.

$$
\text { ANA } 33 \text {-si pero }
$$

JOE - creo que el médico debe, tiene una posibilidad, otra vez - algo así como volver a dis- cutir de eso, con Paulina, y hacer que se DE cuenta de los riesgos que ella le hace correr a su marido y creo que en varios casos, existe la posibilidad de hacerle admitir a la persona que bueno, toca decirlo de todas maneras, aunque sea difícil; y segundo, si de todas formas hay resistencia, pues queda otra posibilidad, hacer una reunión con Paulina y su esposo y entonces $\S$ de de $\S$

\section{(1) $\mathbb{L A U} 1 \mathbb{A}$, Couple}

Fin de la lecture de la vignette: Ce médecin devrait-il dire à Jean que sa femme est séropositive?

ANA 30 -et ben moi je pense que: oui, $<$ petit rire $>$

\section{MON 28 - moi je pense aussi <rire>}

ANA 31 -parce que il y a déjà- la confiance déjà entre le couple elle n'y est plus. parce que bon ben si depuis des années elle a des relations extraconjugales, alors je pense que c'est un tiers qui doit intervenir, dans ce cas

$$
\begin{aligned}
& \text { JOE } 48 \quad \text {-moi c'est OUI MAIS, + } \\
& \text { <rire général> }
\end{aligned}
$$

JOE - OUI MAIS < rires des autres>, parce que déjà quand tu dis la relation de confiance est rompue, oui et non, + dans le sens que c'est toi qui porte un jugement sur le fait que la relation de confiance est rompue §mais je pense§

\footnotetext{
${ }^{8}$ Aquí se trata de la versión suiza de la viñeta. En el caso del corpus parisino la formulación está adaptada a la estructura sanitaria francesa.
} 
ANA $32 \quad-\$ m a i s$ si elle le dit§ pas parce que $\S\{\mathrm{xxx}\} \S$

JOE 49 — c'est je pense que c'est aussi c'est aussi à 'elle d'être amenée à le à un certain moment à le dire, je crois pas que c'est au-, je crois pas que tu peux dire \# simplement comme ça

\section{ANA 33 -oui mais}

JOE - -je pense que le médecin il doit il a il a une possibilité, c'est de nouveau 1 - comme déjà de REdiscuter avec Pauline, de ça, et de l'amener à lui faire RÉaliser les risques qu'elle fait encourir à son mari et je pense que dans un certain nombre de cas, il y a la possibilité de faire admettre à la personne que bon il faut 'quand même le dire, même si c'est dur. et deuxièmement si y a quand même résistance à ce moment-là il y a une autre possibilité, c'est de faire une réunion entre Pauline, son mari et euh $\S$ de de§

A partir de ahora, presentaré ejemplos sacados de discusiones de dos grupos de Lausana, estudiantes de psicología (LAU1A y LAU3B) y, de manera más marginal, de un grupo de París, estudiantes de lingüística (PAR2B).

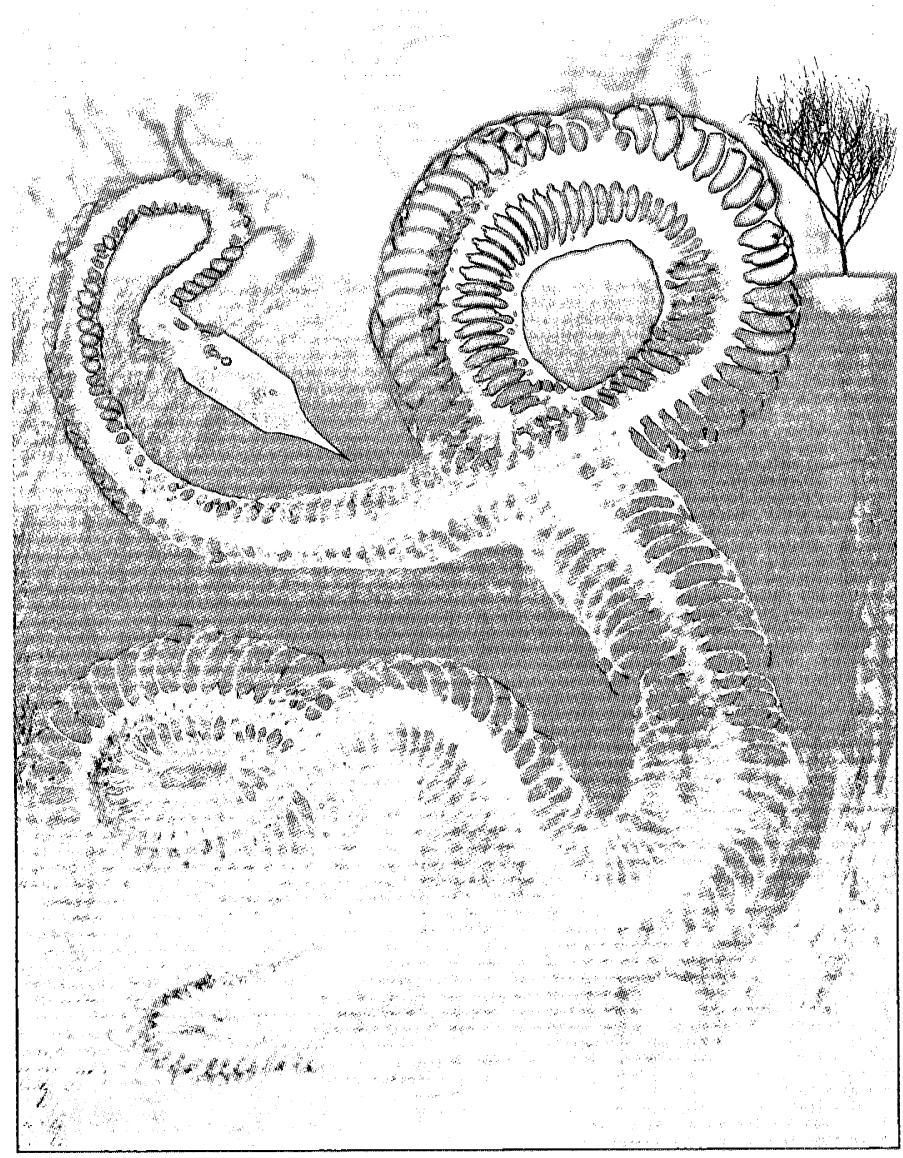

El tipo de actividad en la cual participan los interlocutores, $y$, de manera más específica, la forma como son interpelados por las viñetas, exacerba la dimensión dialógica de toda réplica: los locutores se ven obligados, de entrada, a inscribirse en el contexto propuesto por la viñeta y a responder a él; los enunciados son, primero que todo, enunciados respuesta o enunciados en reacción: respuesta a la solicitud de toma de decisión de parte del animador, reacción a las posturas de los demás.

\section{2. ¿Qué ejes dle amállisisis?}

En teoría y estética de la novela, Bajtín distingue "El diálogo como forma composicional" de la "dialogización interior", el diálogo externo del diálogo interno (Bres, 1998). Esta distinción permite diferenciar los fenómenos que corresponden a la estructura del intercambio verbal, como, por ejemplo, la alternancia de los turnos de habla, las formas de tratamiento, las reglas de encadenamiento, por un lado, de los fenómenos - considerados más específicamente dialógicos- de concurrencia en el seno del enunciado de las palabras propias y las ajenas, de confrontación de la perspectiva propia y de anticipación de la comprensión responsiva $^{9}$, por otro lado.

Esta distinción debe ser considerada en articulación con una segunda (con la cual se la confunde a veces) que opone el dialogismo a distancia con el que se realiza en la inmediatez del intercambio verbal, y que proviene, igualmente, de la dialogización interior:

Cada enunciado aislado representa un eslabón en la cadena de la comunicación discursiva. Sus fronteras son precisas y se definen por el cambio de los sujetos discursivos (hablantes), pero dentro de estas fronteras, el enunciado, semejante a la mónada de Leibniz, refleja el proceso discursivo, los enunciados ajenos, y, ante todo, los eslabones anteriores de la cadena (a veces los más próximos, a veces -en las esferas de la comunicación cultural-muy lejanos) (Batjín, 1982, p. 284).

Sin embargo, es legítimo preguntarse si se trata de fenómenos similares o si la relación dialógica a distancia presenta especificidades en relación con el intercambio cara a cara.

${ }^{9} \mathrm{Y}$ que se descompone igualmente en términos de dialogización interdiscursiva y dialogización interlocutiva. 
Partiré, por lo tanto, de esta doble oposición, sin por esto trazarle límites precisos. Emprenderé el análisis del corpus, tratando los fenómenos que, en los diálogos estudiados, puedan ser atribuidos únicamente a enunciadores distantes o virtuales, para luego observar más detalladamente lo que se teje en el intercambio efectivo cara a cara.

\subsection{Del dialogismo a distancia...}

En el dialogismo a distancia tal como se manifiesta en este corpus, distinguiré tres fenómenos entre los cuales podemos apreciar importantes interrelaciones: la heteroglosia, el interdiscurso ${ }^{10}$ y la representación del discurso del otro.

\subsubsection{La heteroglosia}

La heteroglosia o plurilingüismo interno del enunciado, corresponde a la expresión de diferentes códigos, lenguas, estilos y géneros en el seno de un mismo discurso. En los estudios bajtinianos, constituye uno de los aspectos de la polifonía de las novelas. El tipo de situación examinada aquí se presta poco a la mezcla de códigos y géneros. Aun así, podemos notar que el recurso a argumentos legales realizados por los diferentes sujetos, se acompaña con frecuencia de la adopción de las formas y del estilo del discurso jurídico.

\section{(2) LAU1A, Contrato}

JOE 20 (...) pero ya existe una ley de tipo federal sobre la protección de información, así que todo dato recogido deberá hacerse eh, eh sin que la identidad de la persona pueda ser forzosamente reconocida por fuera de- de estos profesionales de la salud eh (...).

\section{(2) LAU1A, Embauche}

JOE $20 \quad$ (...) mais il y a déjà une loi au niveau fédéral sur la protection des données, donc ça veut dire que toute donnée récoltée devra se faire euh euh sans que l'identité de la personne puisse être forcément identifiable en dehors desde ces professionnels de la santé hein (...).

De esta forma, los sujetos pueden movilizar en una discusión, su conocimiento de otros códigos: haciendo esto, afirman, en cierta manera, su legitimidad para dar una respuesta al dilema. (Salazar y Grossen, 2004a).

\subsubsection{El interdiscurso}

$\mathrm{El}$ interdiscurso (o la intertextualidad) constituye un fenómeno diferente de la heteroglosia ya que corresponde no al uso de distintos códigos, estilos o géneros, sino a la evocación de discursos que han sido enunciados en un momento dado, por otras instancias, en el marco de lo que Bajtín llama la esfera del intercambio cultural.

El hablante no es un Adán, por lo tanto el objeto mismo de su discurso se convierte inevitablemente en un foro donde se encuentran opiniones de los interlocutores directos (en una plática o discusión acerca de cualquier suceso cotidiano) o puntos de vista, visiones de mundo, tendencias, teorías etc. (en la esfera de la comunicación cultural). (Batjín, 1982, p. 284)

En este corpus, el interdiscurso se manifiesta de diversas formas: el recuerdo de leyes ${ }^{11}$ :

\section{(3) LAU3B, Pareja}

MAR $3-(.$.$) pero eh +$ de todas formas hay, hay- el código deontológico hace que tú no tienes derecho a hablarle a alguien sobre la salud de otro. iDe ninguna manera!

\section{(3) LAU3B, Couple}

MAR $3-(.$.$) mais euh +$ de toute façon y a y a- le code déontologique fait que tu n'as pas le droit de t'adresser à quelqu'un concernant la santé de quelqu'un d'autre, exclu!

El discurso genérico que proviene de la doxa o de conocimientos enciclopédicos cuya fuente son otros discursos:

\section{(4) LAU1A, Contrato}

JOE $27-(.$.$) porque el sida se puede ad-$ quirir eh + en cualquier momento, no solamente al cuando uno, cuando uno, cuando uno entra a un trabajo quiero decir \#.

\footnotetext{
${ }^{10}$ Utilizando libremente este término situado más bien en la tradición de Foucault y Pêcheux.

${ }^{11}$ Un mismo fenómeno discursivo puede, de esta forma, corresponder al mismo tiempo a diferentes facetas del dialogismo: en este caso, la cita de la ley (relativa al interdiscurso), implica al igual el recurso al género y al estilo jurídico (relativo a la heteroglosia).
} 


\section{(4) LAU1A, Embauche}

JOE $27-(.$.$) parce que le sida on$ peut l'attraper euh + à n'importe quel moment, pas seulement au moment où on où on où on entre dans un métier j'entends\#

Así como la introducción de nuevos objetos de discurso como presupuestos:

\section{(5) LAU51A Contrato}

JOE 23 - sí pero también existe el famoso grupito de gente que está contagiada sin saberlo.

\section{(5) LAU1A Embauche}

JOE 23 - \$oui mais il y a le fameux petit groupe des gens qui le 'sont sans le savoir

Joël parte de la presuposición de que la existencia del "grupo de gente que está contagiada sin saberlo" es admitida por el resto de los participantes. Podemos pensar aquí en lo que Bres (1998) ha llamado la heterogeneidad oculta, ya que estos enunciados se apoyan de forma implícita en discursos de otros que han sido admitidos como existentes. Por otra parte, es interesante notar que estos enunciados jamás son puestos en duda $u$ objetados en el contexto de las discusiones, al menos para las viñetas consideradas en este estudio. Cuando surgen, corresponden a la explicitación de los principios que garantizan la argumentación: por esto, aparecen como indiscutibles, y permiten a los locutores individuales no ponerse de manifiesto y fundar su opinión sobre algo admitido o compartido. Por lo tanto, sirven a menudo de contexto a la discusión siguiente: es el caso de la evocación de la ley en Joe 20 (ej. 2) en la viñeta contrato o el del - código deontológico en Mar 3 (ej. 3) en la viñeta pareja.

\subsubsection{La representación del discurso del otro} La inscripción del discurso del otro en el enunciado puede tomar otra forma, la del discurso representado, referido, directo o indirecto. Esta categoría presenta, claro está, rasgos comunes con la anterior, pero podemos considerar que el interdiscurso corresponde a lo que circula en una comunidad dada, a lo que es admitido, o aun asumido, como verdadero y en el cual la doble enunciación puede ser ocultada; mientras que en el caso de la cita o de la representación del discurso de otro, la pluralidad de los enunciadores es explicitada y puesta en escena.

Este corpus presenta un número relativamente importante de discursos representados pero se trata, sobre todo, de discursos ficticios:

\section{(6) LAU1A, Contrato}

MON 11 -a mí me parece trivial que, que, que inmediatamente se haga pasar un examen al personal, como diciendo "bueno, de entrada no les tenemos confianża y pues vamos a verificar".

\section{(6) LAU1A, Embauche}

MON $11-m o i$ je trouve trivial de de de ouais tout de suite faire passer un test comme ça au \# personnel pour dire "alors on vous fait pas confiance dès le départ et puis on va vérifier".

En este ejemplo, Monique hace uso del discurso representado para poner en escena, de forma exagerada, la posición que ella atribuye a sus interlocutores. En otros casos, la puesta en escena de discursos ficticios se inscribe en continuidad con la propia voz del locutor:

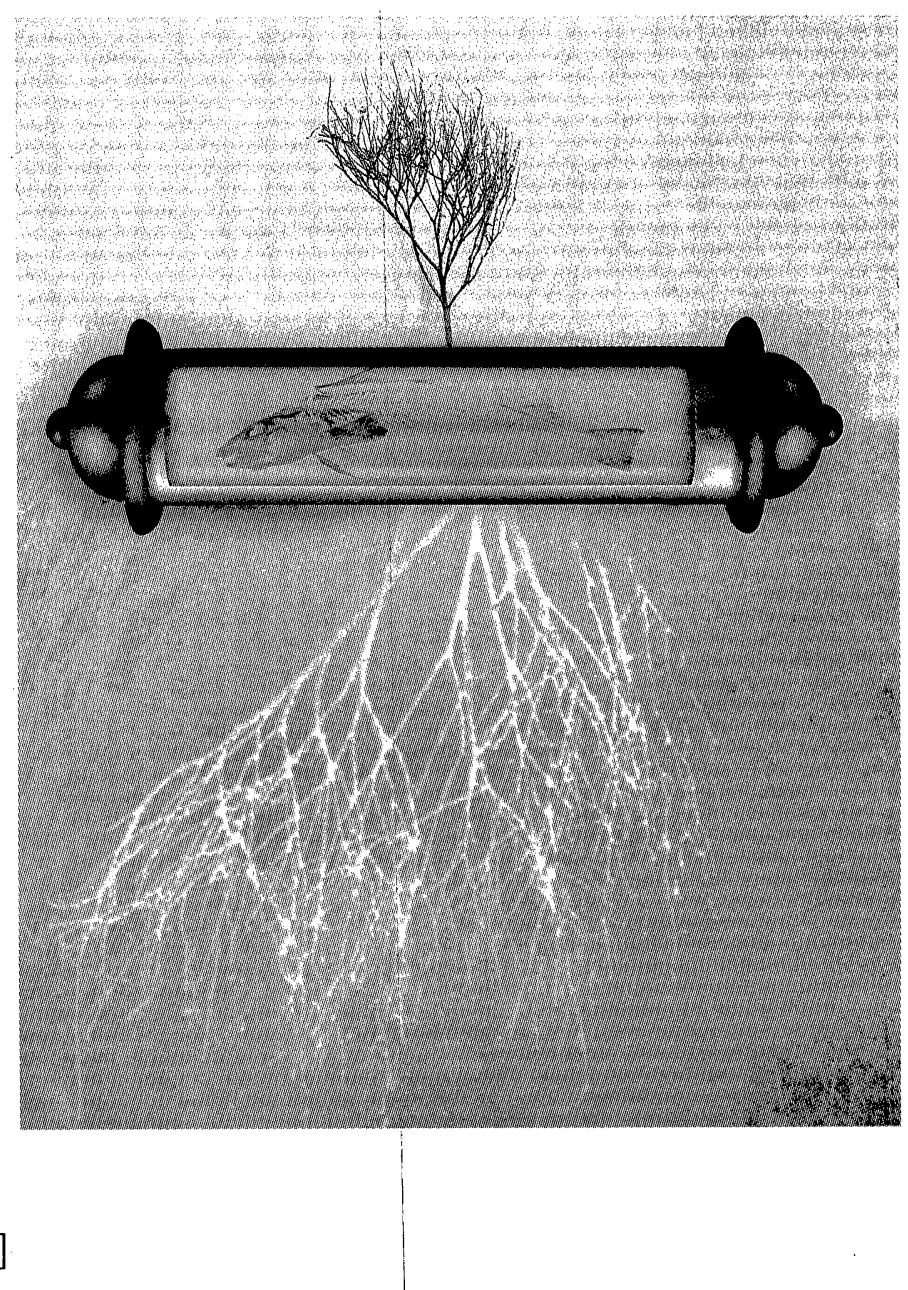




\section{(7) $\mathbb{L} \mathbb{A} \mathbb{U} 1 \mathbb{A}$ Contrato}

JOE $20 \quad-(.$.$) pues, + ahí justamen-$ te <risa $>$ es un poco <risa general> un poco el jurista que va, que va, que va a sostener, que va a decir que + de todas formas él- eh porque va a llamar a juristas que le dirán que sería posible imaginarse cosas así, pero que ya existe una ley a nivel federal sobre la protección de la información, y eso significa que todo dato recolectado deberá hacerse eh, eh, sin que la identidad de la persona pueda ser obligatoriamente identificable por fuera de esos profesionales de la salud eh, \# así que + toca- eso me parece me par - eso me parece ya muy complicado de imaginar.

\section{(7) $\mathbb{L} \mathbb{A} \cup 1 \mathbb{A}$, Embauche}

JOE $20-(\ldots)$ alors, + là justement < rire> c'est un peu <rire général> un peu le juriste qui va qui va qui va qui va alimenter, qui va dire que + de toute façon il se- euh, parce qu'il va faire appel à des juristes qui lui diront que ce serait possible d'imaginer de telles choses mais il y a déjà une loi au niveau fédéral sur la protection des données, donc ça veut dire que toute donnée récoltée devra se faire euh euh sans que l'identité de la personne puisse être forcément identifiable en dehors des- de ces professionnels de la santé hein, \# donc + il faut- ça me paraît ça me par- ça me paraît déjà très compliqué à imaginer.

Asistimos aquí a una puesta en escena compleja: al mismo tiempo que evoca su propio estatus de jurista, Joël introduce personajes ficticios que son juristas, a la vez diferentes y parecidos a él. Es a estos juristas a quienes les atribuye la evocación de la ley. Pero un momento después, a partir del marcador de reformulación y eso significa que, nos encontramos con un enunciado que podría ser atribuido igualmente a Joël como enunciador: Joël juega con el argumento de autoridad ("juristas que le dirán"), pero esta autoridad es, al mismo tiempo, su semejante, lo que le permite concluir con su propia voz: "eso me parece ya muy complicado".

La representación de los discursos de otros, constituye una herramienta privilegiada para la expresión de diversos puntos de vista en la discusión. De forma general, el dialogismo a distancia - generalmente virtual- constituye un recurso fundamental para la argumentación. Está, por lo tanto, implicado directamente en el dialogismo del diálogo inmediato.

\section{4. ...all diallogismo dell diállogo}

Cuando nos interesamos en los enunciados inscritos en un diálogo efectivo, resaltan las relaciones que se tejen entre ellos a lo largo de los intercambios, lo que Bajtín describe diciendo:

Cada enunciado está lleno de ecos y reflejos de otros enunciados con los cuales se relaciona por la comunidad de esfera de la comunicación discursiva. Todo enunciado debe ser analizado, desde un principio, como respuesta a los enunciados anteriores de una esfera dada (el discurso como respuesta es tratado aquí en un sentido muy amplio): los refuta los confirma, los complementa, se basa en ellos, los supone conocidos, los toma en cuenta de alguna manera (Batjín, 1982, p. 281).

Estas diferentes relaciones corresponden a las que son desplegadas en un diálogo común y corriente: relaciones de continuidad ("se apoya sobre ellos, los supone conocidos"), de respuesta y de posicionamiento ("los refuta, los confirma"), a lo que se suma la anticipación de las respuestas del interlocutor. De esta manera, sin tener en cuenta los aspectos más mecánicos del diálogo externo (por ejemplo, la alternancia de los turnos de habla), podemos subrayar cuatro facetas del dialogismo en el diálogo.

\subsubsection{El enunciado como respuresta}

Detengámonos, primero que todo, en el hecho de que el enunciado es respuesta a un discurso anterior, y aquí, de manera más específica, a la pregunta de la viñeta y a los posicionamientos de los demás interlocutores. Los locutores despliegan diversos movimientos de oposición, acuerdo, argumentos y contra-argumentos... aspectos que apuntan a la confrontación de una palabra con la palabra del otro. Podemos ver esto en el siguiente extracto:

\section{(8) $\mathbb{P A R} 2 \mathbb{B}$, Pareja}

NOE 3 -pue(s) cierto que tendría que decirle a: + que tendría que decirle al marido, sí efectivamente! ++ porque, de una parte, es el médico de los dos, ++ es verdad que en ++ \{bueno\} cuando dos personas están casadas ya no necesitan: + normalmente! +: protegerse, ++ además que,:: + + en el matrimonio:-, en realidad se utilizan más los medios anticonceptivos que los de protección contra las:- + las enfermedades sexualmente transmisibles, pero es cierto que:: 
++ ella puede muy fácilmente eh contaminar a su esposo.

CAR 2 -iyo no estoy de acuerdo!

SYL 2 -iyo tampoco! $\S$

MAR $2-\S$ yo creo que +++ yo creo que el médico no tiene nada que decir::, + no es: a ver ++ no es su rol + no se supone a que está para + hacer cambiar a las parejas y: $\S$ a la esposa le toca:

SYL $3-\S$ sí, pero si la esposa no le dice nada y no decide decirle nunca eh $\S$

CAR $3-\S$ no pero justamente + que (e) \# el médico eh: le diga a la esposa que es ella

SYL 4 -sí pero-

CAR 4 -ique toc-que la lleve a decirle ella!

MAR 3 -ihay que responsabilizarla a ELLA! pero no creo que sea diciendo que eh:: eh: me parece que no es el médico que al decirle a Juan, < rápido> bueno, retomemos los nombres, a Juan que:: que su esposa es seropositiva que va a arreglarlo todo:!

\section{(8) PAR 2B, Couple}

NOE $3 \quad-b(i) e n$ c'est vrai qu'i(l) d(e)vrait l(e) dire à:, + qu'i(l) d(e)vrait l(e) dire au mari oui effectivement! ++ pa(r)ce que d'une part il est le médecin des deux, ++ et c'est vrai qu(e) dans::, $++\{$ enfin $\}$ quand deux personnes sont mariées elles n'ont plus besoin de::, + normalement! + de: $+\mathrm{s}(\mathrm{e})$ protéger, ++ surtout que,:: ++ dans $1(\mathrm{e})$ mariage en fait la:-, + on $\mathrm{s}(\mathrm{e})$ sert plus de moyens de contraception que $d(e)$ moyens $d(e)$ protection contre les:- + les maladies sexuellement transmissibles, mais c'est vrai que:: ++ elle peut très facilement euh: + contaminer son époux.

CAR $2-$ moi j(e) suis pas d'accord!

SYL $2 \quad$-non moi non plus! §

MAR $2-\S$ moi j(e) crois qu- +++ moi $\mathrm{j}(\mathrm{e})$ crois qu(e) le médecin il a rien à dire et que::, + c'est euh: enfin ++ c'est pas son rôle + il est pas là poure + pour faire bouger les couples et: $\S$ c'est à la femme de::
SYL $3 \_-\S$ oui mais si la femme elle lui dit rien et elle se décide pas un jour à lui dire euh $\S$

CAR $3-\S$ non mais justement + qu(e) \# le médecin euh: dise à la femme que c'est à elle

SYL 4 -oui mais-

CAR 4 -qui f- qui la pousse à lui dire elle!

MAR 3 -faut la responsabiliser ELLE! mais $\mathrm{j}(\mathrm{e})$ crois pas $\mathrm{qu}(\mathrm{e})$ soit en disant hein:: hein: i(l) m(e) semble que c'est pas au médecin en disant à Jean, < rapide >là on va $\mathrm{r}(\mathrm{e})$ prendre les noms ${ }^{\circ}$, à Jean que:: sa femme est séropositive que ça va tout arranger enfin:!

En este segmento, Sylvie, Carine y Marine se oponen frontalmente a Noël que ha propuesto levantar el secreto médico. Lo hacen en tres tiempos: primero marcando su posición ("iYo no estoy de acuerdo!"), luego, gracias a un argumento ba

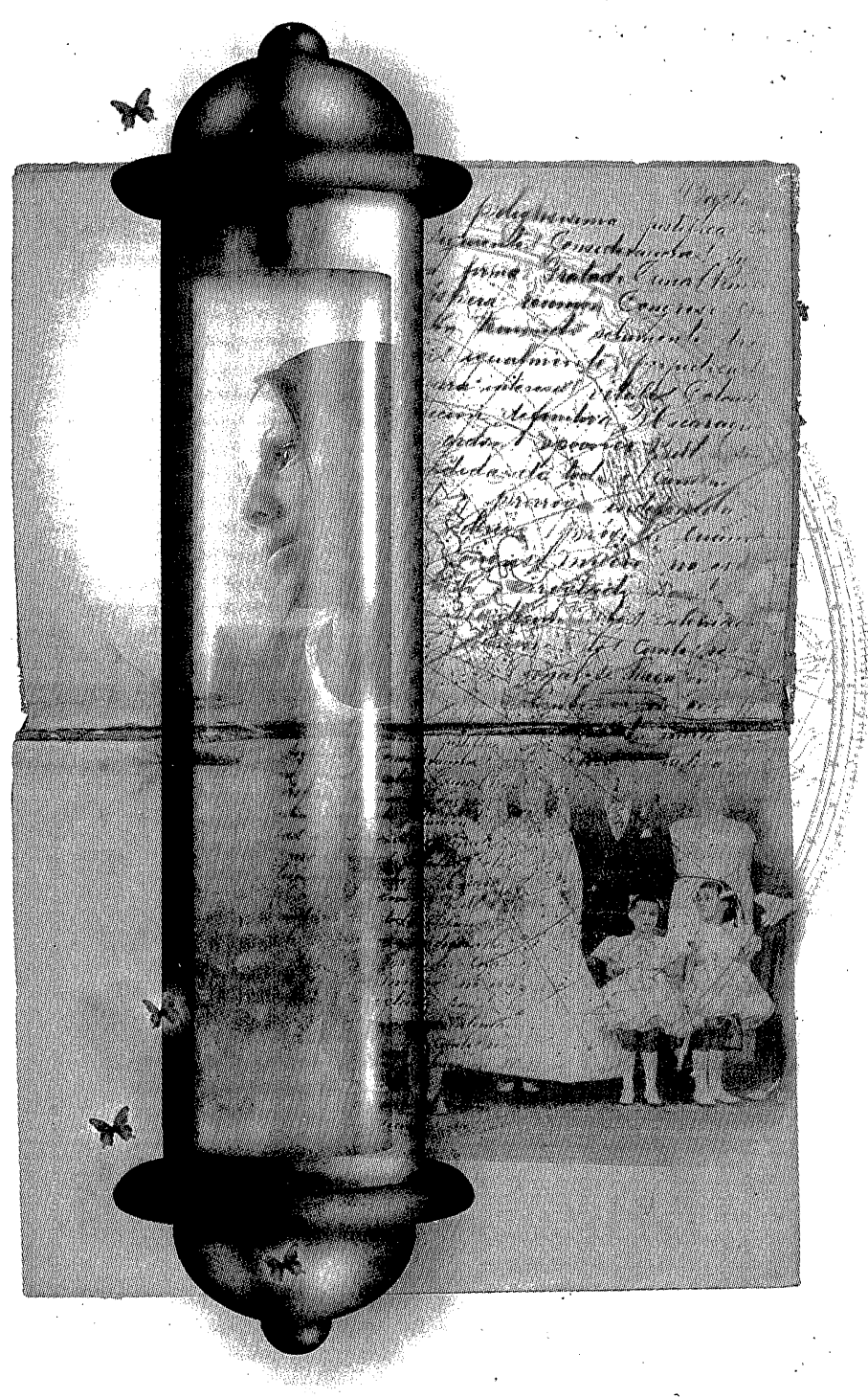


sado en la definición del papel del médico ("no se supone que + está para hacer cambiar a las parejas"), y, finalmente, proponiendo una solución de compromiso: responsabilizar a la esposa.

Estos movimientos son considerados, la mayoría de las veces, como correspondientes al diálogo externo: están determinados por la situación de comunicación y por el valor de los enunciados que circulan. De otra parte, podemos pensar que por esto Bajtín considera, de forma un tanto contradictoria con sus propias posiciones, el discurso polémico como menos dialógico, ya que la confrontación se manifiesta en dos enunciados de dos interlocutores diferentes... Sin embargo, y contrariamente a lo que Bajtín afirmaba, estos enunciados contienen, al mismo tiempo, en su seno, un diálogo potencial. Retomaremos posteriormente este asunto.

\subsubsection{La anticipación de la comprensión responsiva}

Pero el enunciado no corresponde únicamente-a un posicionamiento con respecto a lo que se ha dicho, también está orientado hacia la respuesta que puede recibir. Todo discurso anticipa la comprensión de su interlocutor. Podemos, entonces, constatar una serie de fenómenos que proyectan esta recepción y las enunciaciones potenciales consecuentes que se sitúan con relación a éstas.

Esto se manifiesta en el corpus, en los movimientos de concesión o de justificación que se adelantan a posibles contra-argumentos. Observemos, por ejemplo, los movimientos descritos por Monique en el turno siguiente:

\section{(9) LAU1A, Contrato}

MON $11-a$ mí me parece trivial ${ }^{12}$ que, que, que sí, inmediatamente hacer pasar un examen al personal, como diciendo "bueno, de entrada no les tenemos confianza y pues vamos a verificar" de otra parte, está claro que: pues sí \# es verdad que ciertas personas se pueden ver obligadas a ocultar su seropositividad porque justamente saben que eso representa un riesgo para no ser contratadas, así que es: cierto, pero por otro lado encuentro algo trivial hacerlo de esa forma $\S$

\section{(9) LAU1A, Embauche}

MON $11-$ moi je trouve trivial de de de ouais tout de suite faire passer un test comme ça au \# personnel pour dire "alors on vous fait pas confiance dès le départ et puis on va vérifier", d'un autre côté c'est clair que: ben voilà \# c'est vrai que certaines personnes peuvent être amenées à ca'cher leur séropositivité parce que justement elles savent que elles ont encore un risque de 'pas être engagées, donc c'est: vrai, mais d'un autre côté je trouve que c'est c'est un peu trivial quoi de s'y. prendre comme ça§

Monique rechaza la idea de los exámenes preventivos. Mientras afirma esta posición hace una concesión adelantando por sí sola un argumento que podría serle justamente replicado (y que nadie ha mencionado hasta entonces): "es verdad que ciertas personas se pueden ver obligadas a ocultar su seropositividad"; de esta forma, demuestra que no solamente espera una refutación, sino que también prevee la forma que ésta puede tomar.

Es importante señalar que aun si observamos aquí fenómenos de anticipación de la comprensión responsiva en la relación cara a cara con un interlocutor claramente identificado, éstos existen igualmente en el dialogismo a distancia, en el caso de diálogos no inmediatos, tales como los que podemos notar entre textos escritos. Éste es un buen ejemplo de la continuidad que existe entre dialogismo del diálogo y dialogismo con el interdiscurso.

\subsubsection{La imbricación del discurso de uno en el discurso del otro}

Lo que podemos observar en el análisis de los intercambios dialogales es el extremo entrelazamiento de las palabras, el compartir no solamente los temas sino también las formas lingüísticas, y las diferentes maneras de tener en cuenta la palabra ajena.... En efecto, el discurso de cada locutor cuenta con numerosas huellas de su recepción-integración del discurso de sus interlocutores, esto debido a que el discurso de uno es el material a partir del cual se construye el discurso del otro. Esta complejidad se manifiesta de dos formas dominantes:

\section{a. La continuidad y las presuposiciones}

Por supuesto, se piensa inmediatamente en los fenómenos de continuidad temática y referencial.

\footnotetext{
${ }^{12}$ En el original en francés el uso de trivial por la locutora es igualmente sorprendente. Por eso hemos decidido conservar la traducción literal.
} 
Tomemos el inicio de la respuesta a la viñeta de la pareja del grupo LAU3B.

\section{(10) LAU3B, Pareja}

ANI - -... ¿El médico debería decirle a Juan que su esposa es seropositiva? $<2$ segundos $>$ eso, $<2$ seg.>

FRE 2 -iqué conflicto tan horrible! $<$ risa $><$ risa general $>$

CLA 2 -creo que estamos de acuerdo en que no debería decirle, pero encuentro que sería más bien actuar con la señora lo que él debería hacer, ya que tiene una relación de confianza y que puede hablar con los dos, es más justo que sea la esposa la que le diga al esposo, así por lo menos \# en $\{x x\}$ porque si es el médico, la pareja podría entrar en crisis, cuando semejante, semejante información, entraría seguramente en crisis.

\section{(10) LAU3B, Couple}

ANI. $\quad-(.$.$) le médecin devrait-il dire à$ Jean que sa femme est séropositive? $<2$ s. $>$ voilà, $<2$ sec $>$

FRE 2 -quel horrible conflit! < rire> $<$ rire général $>$

CLA 2 -je crois qu'on est d'accord qu'il devrait pas le dire, mais je trouve que ce serait plutôt une action sur la sur la dame qu'il devrait faire, comme il a instauré une relation de confiance et puis qu'il peut parler aux deux, c'est plus juste qu'i(l) soit la femme de dire au mari, déjà comme ça \# en $\{\mathrm{xx}\}$ parce que si c'est le médecin, déjà le couple qui pourrait entrer en crise lorsqu'une telle une telle information entrerait certainement en crise

Se pueden subrayar los siguientes fenómenos:

- Las anáforas: le, el médico que se construyen en la relación entre el turno de habla de Clara con el de la animadora.

- La repetición de formas: esposa, debería, decir, relación de confianza, médico que circulan de nuevo de una habla a la otra y constituyen las fuentes lexicales del discurso de Clara.

- La constitución de presuposiciones tales como la nominalización qué conflicto tan horrible o semejante información. En el primer caso, conflicto califica la situación que acaba de ser presentada por la lectura de la viñeta. Pero el enunciado lo presenta como admitido y remite, de esta manera, al discurso de la animadora. Ocurre lo mismo con semejante información que toma sus fuentes en el texto de la viñeta "decirle a Juan que su esposa es seropositiva". Al mismo tiempo que vuelve a elaborar el texto, Clara lo inscribe mediante la expresión semejante en relación con lo dicho anteriormente: de esta forma, un objeto se construye como compartido, y este compartir se ve reforzado por la locutora.

Podríamos considerar que estos fenómenos corresponden al campo de la cohesión textual y no tienen nada que ver con el dialogismo. Sin embargo, lo que demuestran estos ejemplos es, en realidad, lo contrario, es decir, que las fuentes de muchas expresiones referenciales producidas por un locutor dado en un momento dado, se encuentran en el discurso del otro. La continuidad sería, por lo tanto, primero dialógica antes que monológica.

\section{b. La continuidad señalada}

Este proceso de imbricación puede ser marcado, entre otros, por expresiones o giros específicos que remiten de manera explícita a la existencia de un fondo común y que manifiestan, por lo tanto, que el locutor tiene en cuenta el discurso del otro. De esta forma, en el ejemplo anterior, tenemos, "ya que tiene una relación de confianza", que repite una expresión del discurso de la animadora marcándola como una forma enunciada anteriormente.

Se suma a esto el recurso a la cita del discurso del interlocutor, ya sea repetido o reformulado - a lo que Roulet (1985) llamó la repetición diafónica-:

\section{(11) LAU1A, Contrato}

ANA 23 -sí, claro, bueno yo diría verdaderamente eh cuando se sabe exactamente, en las situaciones donde hay altos riesgos, pienso que es de todas formas mejor saberlo, pues, no sé, me parece: por honestidad con la paciente también \# porque quiero decir, si uno se va a hacer curar tiene confianza \# y pues, pero es verdad que hay que hacer la distinción entre los diferentes- diferentes campos, donde quiero decir, medicina general no hay riesgos, pero hay casos + sí, operación quirúrgica: eh no sé, me haría más preguntas, YO por ejemplo, si fuera paciente me gustaría que me lo dijeran \#<muy suavemente> no sé. 
MON 15 - sí, yo creo que hay un gran problema con el secreto profesional pues, porque no está siendo respetado porque-si, si dices si, si eres paciente te gustaría saberlo, los pacientes deben saberlo, pero entonces en realidad si se hacen si se hacen esos exámenes ¿quién estaría hábilitado para tener los resultádos después? \# ¿la gente que contrata? ¿los colegas? \# ¿o el personal? No lo van a poner en un cartel anunciando $\S$ que es seropositiva $\S$, entonces ¿qué van a hacer con esos resultados después?

\section{(11) $\mathbb{L A U} 1 \mathbb{A}$, Embauche}

ANA 23 -ouais tout à fait, bon moi je dirais vraiment euh dans les cas où on sait exactement dans les situations où il y a des hauts risques, je pense que c'est quand même bon de le savoir enfin je sais pas, il me semble: par honnêteté vis-à-vis de la patiente aussi \# parce que je veux dire si on va se faire soigner on a confiance \# et pis mais c'est vrai qu'il faut faire la distinction entre les différents- différents domaines, parce que je pense qu'il y a des domaines où on je veux dire médecin généraliste on risque rien, mais des des cas + oui opération chirurgie: euh je sais pas je me poserais déjà plus de questions, MOI par exemple si j'étais patiente je voudrais le savoir \#<très doucement $>$ je sais pas.

MON 15 -ouais moi je pense qu'il y a un grand problème du secret professionnel alors, parce qu'il est plus du tout maintenu, parce que si si tu tu dis oui si t'es patiente tu aimerais le savoir, les patients doivent le savoir, mais alors en fait si on on fait ce test mais qui est habilité à avóir le résultat après? \# les gens qui engagent? les collègues? \# ou bien le personnel? on va pas l'afficher §sur elle qu'elle est séropositive§, alors qu'est-ce qu'on va faire de ces résultats après?

Vemos aquí cómo Monique retoma las palabras de Ana y construye una reformulación interpretativa de su discurso, reformulación que atribuye a Ana una posición tal vez más radical de lo que ésta había expresado, lo que le permite después desarrollar su propio razonamiento. De esta forma, el discurso de Monique no sólo lleva las huellas del de Ana sino que se construye sobre esa base.

Esto me lleva a hacer un paréntesis: todos estos fenómenos de imbricación, de dependencia del habla de uno con respecto al habla del otro, no provienen, únicamente, del simple retomar sus pala- bras exactas. Están asociados, por lo general, con un trabajo de reformulación: lo que está inscrito en el fondo común del diálogo, también ha sido objeto de la comprensión responsiva activa del locutor. Esto se ve más claramente en las inferencias que los locutores hacen a partir de lo que ha sido dicho:

\section{(12) $\mathbb{L A U} 3 \mathbb{B}$, Pareja}

CLA 2 -creo que estamos de acuerdo que no debería decirle, pero encuentro que sería más bien con la señora con quién él debería hacer algo. (...) y entonces sería la esposa la que debería decir, y además como tiene acceso a los dos, a los da las dos personas, creo que el médico debería realmente intentar convencer a la madre, eh la madre \# la esposa antes de preguntarse si debe decírselo al esposo. \# $\mathrm{O}$ por lo menos intentarlo en esa dirección, \# debería trabajar en esa dirección creo yo

$$
\text { (...) }
$$

MAR 3 -bueno no es eh: creo que hayen algún momento hay que ver- el, el secreto profesional de este médico indica que no tiene derecho a decirle nada al marido con respecto a su esposa, punto, es, es el código deontológico ético médico. No tiene opción, y la, la, la orientación de trabajar con la esposa con respecto a su seropositividad una vez que haya pasado el choque.

\section{(12) $\mathbb{L} \mathbb{A} U 3 \mathbb{B}$, Couple}

CLA 2 -je crois qu'on est d'accord qu'il devrait pas le dire, mais je trouve que ce serait plutôt une action sur la sur la dame qu'il devrait faire (...) et alors c'est à la femme de dire, et plus comme il a accès à les deux aux $\mathrm{d}$ - à les deux personnes, je trouve que le médecin devrait vraiment essayer de de convaincre la mère euh la mère \# la femme avant de se poser la question s'il doit le dire ou pas au mari . \# au moins faire une tentative dans sa direction, \# ce serait celle-là la direction à travailler à mon avis,

$$
\text { (...) }
$$

MAR 3 -bon c'est pas euh: je crois qu'il y a- quelque part il faut voir- le le secret professionnel de ce médecin indique qu'il n'a pas le droit de dire quoi que ce soit au mari concernant sa femme, point. c'est c'est le code déontologique éthique médical. il y il y a pas le choix. et le le l'orientation de travailler avec la femme concernant sa séropositivité une fois qu'elle a absorbé le 'choc. 
Aquí, Martha retoma la proposición hecha por Clara recalificándola. El determinante definido y la substitución por un casi-sinónimo (dirección/ orientación) ponen de manifiesto que ella comparte, e incluso ancla su discurso en el de su interlocutora... pero, al mismo tiempo aporta algo nuevo, ya que Clara jamás ha dicho que el médico debía trabajar con la esposa a propósito de la seropositividad...

Estos dos últimos ejemplos muestran hasta qué punto el dialogismo supone, a la vez, la puesta en escena de enunciadores diferentes y, en este caso, de enunciadores que son interlocutores, y cierto grado de divergencia ya que esta puesta en escena no es el reflejo del discurso tal como efectivamente se desarrolló. El discurso retomado es trabajado y modificado por la recepción que se hace de él. El dialogismo está igualmente presente en esta tensión creada entre el discurso de uno y el discurso ajeno...

\subsubsection{La heterogeneidad enunciativa}

Como pudimos verlo, en el seno del enunciado se desarrolla, al mismo tiempo, otro diálogo, el del autodialogismo (Bres, 1998; Bres y Vérine, 2002).

Quisiera proponer aquí la idea que este fenómeno corresponde a la proyección dialogal (o a las fronteras entre otro tipo de exterioridad e interio-

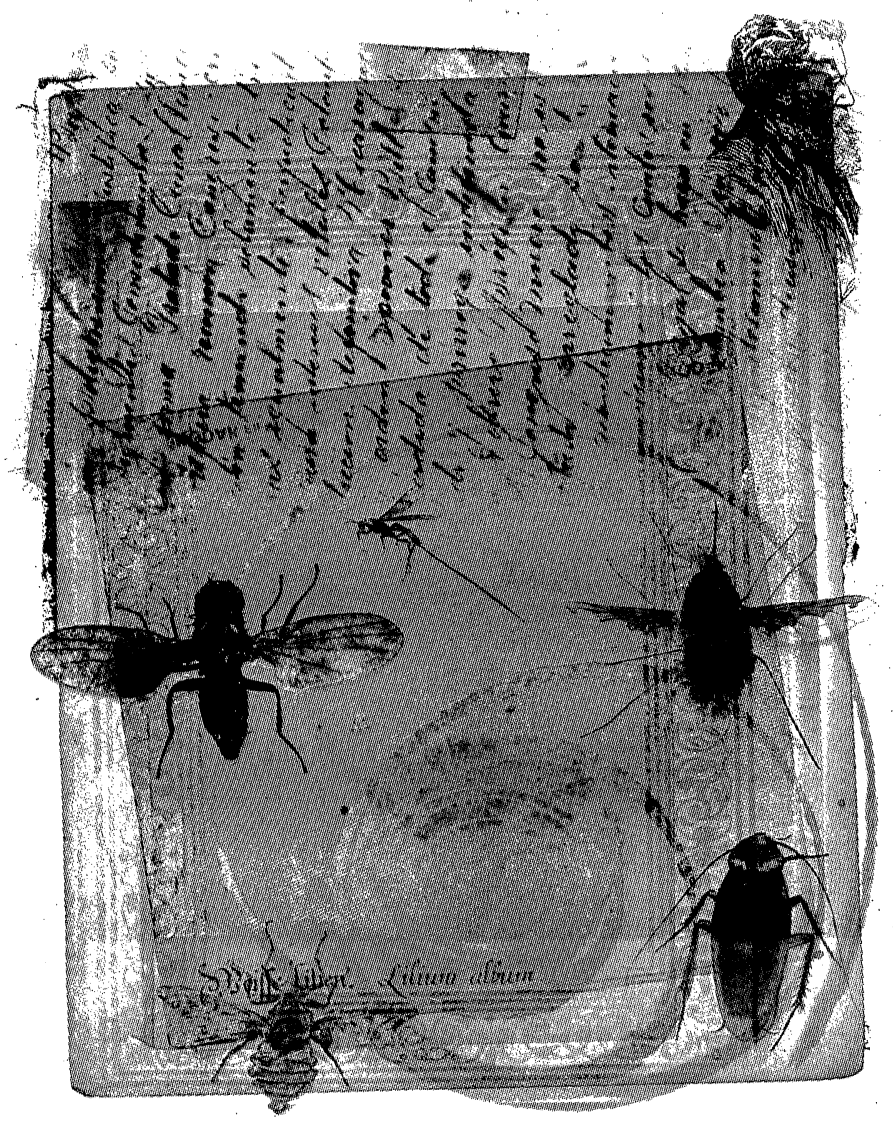

ridad) de las modalidades, las modulaciones del discurso o los comentarios metaenunciativos, etc. Puede sorprender encontrar aquí estas categorías lingüísticas o discursivas puesto que se les considera habitualmente como fenómenos específicos de la dimensión monologal de la elaboración del discurso.

Ahora bien, estas formas corresponden con frecuencia, como claramente lo muestra Vion (2001), a un desdoblamiento o dualidad enunciativa. Cuando se describen las modalidades o los comentarios metaenunciativos se subraya, generalmente, el hecho de que el locutor expresa o pone en escena voces que manifiestan perspectivas diferentes y que pueden ser atribuidas a un enunciador no especificado o, bien sea, asumidas por el locutor (quien dibuja entonces dos enunciadores correferentes). En todo caso, en numerosas ocasiones, un enunciado de este tipo conlleva un posicionamiento en relación con un discurso representado como otro.

Es el caso de la negación, cuya dimensión dialógica ha sido ampliamente estudiada, Ducrot (1980) particularmente, ha distinguido la negación polémica -que tiene una expresión dialogal- de la negación descriptiva, que corresponde, en principio, a un diálogo cristalizado, no desplegado en la alternancia de los turnos de habla.

En el corpus estudiado aquí, la negación se inscribe con frecuencia en una dimensión polémica. La mayoría de las ocurrencias acompañan un movimiento de oposición explícita al discurso del otro o a sus implicaciones: citemos el siguiente comienzo de turno de habla que está en desacuerdo con la pregunta "¿debería decirle?”.

\section{(13) LAU3B, Pareja}

MAR 3:-bueno no es eh: creo que hayen algún momento hay que ver- el, el secreto profesional de este médico dice que no tiene derecho a decirle nada ál marido con respecto a su esposa, punto, es, es el código deontológico ético médico. no tiene opción [...]

\section{(13) LAU3B, Couple}

MAR 3 -bon c'est pas euh: je crois qu'il y a- quelque part il faut voir- le le secret professionnel de ce médecin indique qu'il n'a pas le droit de dire quoi que ce soit au mari concernant sa femme, point. c'est c'est le code déontologique éthique médical. il y il y a pas le choix [...] 
Sin embargo, en otros casos, la negación no se construye en oposición abierta a un enunciado anterior. Ella sugiere, en contraste, la posición del enunciador interlocutor:

\section{(14) $\mathbb{L} \mathbb{A} \mathbb{U} 1 \mathbb{A}$, Contrato}

MON 19 -bueno eso, lo dudo, pero <risa>, pienso de todas formas que- yo- si, estoy de acuerdo con el hecho de que en el área de la salud, eso debe estar claro, así que no diría, en absoluto no, pero pienso que: diría si, pero pienso también que: no se puede tener un término medio \# con eso +

\section{(14) $\mathbb{L} \mathbb{A} \mathbb{U} 1 \mathbb{A}, \mathbb{E m b a u c h e}$}

MON 19 -alors ça 'moi j'en doute 'mais $<$ rire >, je pense quand même que- je- ouais je suis d'accord avec le fait que dans les métiers de la santé, il faut que ce soit clair ça, donc euh j(e) dirais pas du tout non, mais je pense que: je dirais oui, mais je pense aussi que: en fait on peut pas avoir de demi-mesure \# avec ça +

Aquí, el enunciado negativo atribuye a los interlocutores - y en particular a Joël- la posición de quien asume un "término medio". Aunque, al mismo tiempo, él no puede ser considerado a partir de sus palabras, como el responsable de esta calificación. Por lo tanto, el límite entre oposición efectiva y oposición construida por el discurso no es siempre claro. La negación descriptiva se inscribe necesariamente en el debate en curso donde tiene un fundamento dialogal..

Éste es también el caso de los comentarios metaenunciativos, de la modalización y de las modulaciones del discurso, que me permitiré reagrupar en una sola categoría aunque presenten, por otro lado, diferencias cualitativas fundamentales. Propongo que se los consideren como movimientos segundos en relación con un dictum (Bally, 1942), efectivamente enunciado o por enunciarse. Estos movimientos que suponen una mirada, un comentario del sujeto acerca de lo que está diciendo, aparecen integrados en el enunciado que contiene el dictum o pueden constituir otro enunciado.

Pasemos en revista estos tres tipos, sumamente frecuentes e importantes en este corpus, ya que muestran cómo el sujeto se las arregla con sus posiciones, con lo que da por sentado y con sus vacilaciones.
Propongo que consideremos las modulaciones como movimientos ${ }^{13}$ que introducen un matiz, una corrección o un cambio de orientación en el discurso:

\section{(15) IAUU1A, Contrato}

JOE $20-(.$.$) esto me parece, esto me$ par- esto me parece ya de por si muy complicado de imaginar en el sentido en que- existe el principio de protección de la personalidad y de la información \# que es bastante parecido al principio del secreto médico \# que es \# pre-existente, así que eh $<3$ seg. $>$ si pues, en cuanto al principio, sería necesario ver en qué, en cuál el, los datos son muy vagos, habría que ver en qué campo profesional $\S$ por qué $\S$

(...)

JOE 21 -existen campos con riesgo también, entonces $\S$

\section{(15) $\mathbb{L A} \mathbb{U} 1 \mathbb{A}, \mathbb{E m b a u c h e}$}

JOE 20 - (...) ça me paraît ça me par- ça me paraît déjà très compliqué à imaginer dans le sens où on est- il y a le principe de protection de la personnalité et des données \# qui qui est assez proche du principe du secret médical \# qui est \# déjà préexistant, donc euh $<3 \mathrm{~s}$. $>$ ouais quant au principe, faudrait aussi voir dans quel so- c'est très vague la la la donnée, faudrait voir dans quel domaine professionnel §parce que§

$$
\text { (...) }
$$

JOE 21 -il y a des domaines à risque aussi donc§

Aquí Joël comienza afirmando un principio para luego restringir su alcance diciendo. "habría que ver". Este movimiento no introduce solamente un nuevo elemento de contenido sino que corresponde a una manera de posicionarse en relación con aspectos categóricos de su aserción anterior.

Por modalización se entiende todo comentario del sujeto sobre su posición como enunciador, sobre su capacidad para afirmar algo $0^{14}$.

\footnotetext{
${ }^{13}$ Me refiero, por lo tanto, a fenómenos diferentes a los que Vion (2001) llama modulación.

${ }^{14}$ La categoría es aquí más amplia que la que propone Vion (2001).
} 


\section{(16) LAU1A, Contrato}

ANA 23 -pienso que es mejor saberlo de todas formas, en fin, pues, no sé, me parece: por honestidad con la paciente también.

\section{(16) LAU1A, Embauche}

ANA 23 -je pense que c'est quand même bon de le savoir enfin je sais pas, il me semble: par honnêteté vis-à-vis de la patiente aussi

En este ejemplo, la modalización (pienso) está integrada en el mismo enunciado que el dictum o constituye por el contrario ("en fin, no sé, me parece") un movimiento distinto al del portador del dictum.

En fin, los sujetos pueden hacer comentarios metaenunciativos y metadiscursivos sobre el desarrollo o el contenido del discurso:

\section{(17) LAU1A, Contrato}

ANI $38 \quad-\S$ ustedes $\S$ piensan en qué, por
ejemplo?

JOE $25-$ No tengo realmente una idea precisa, lo confieso, pero, pero es cierto que si +

\section{(17) LAU1A, Embauche}

ANI 38 - $\$$ vous§ pensez à quoi par exemple?

JOE 25 -j'ai pas vraiment envie d'idée précise je l'avoue, mais mais c'est vrai de ouais +

Sin embargo, como lo muestra Bajtín, no existen fronteras netas entre el autodialogismo y el heterodialogismo:

El habla cotidiàna práctica; trata del discurso colmado de ataques indirectos al otro, de comentarios maliciosos, etc. A ella pertenece también todo discurso humilde, tortuoso, que de antemano se niega a sí mismo, con miles de reservas, concesiones, subterfugios, etc. Un discurso semejante parece subestimarse en presencia o en presentimiento de la palabra ajena, de la respuesta, de la objeción.

La manera individual en que un hombre acostumbra estructurar su discurso se determina en gran medida por su propia percepción de la palabra ajena y por sus modos de reaccionar a ella. (Batjín, 1986, p. 274)

Por lo tanto, estos movimientos no están únicamente autoorientados. Tienen, sobre todo, una razón de ser en el diálogo. Por ejemplo, es difícil distinguir las modulaciones de la anticipación de la comprensión responsiva. Si tomamos un fragmento examinado anteriormente podemos observar:

\section{(18) LAU1A, Contrato}

MON 11 -a mí me parece trivial que, que, que sí, inmediatamente hacer pasar un examen al personal, como diciendo "bueno, de entrada no les tenemos confianza y pues vamos a verificar" de otra parte, está claro que: pues sí \# es verdad que ciertas personas se pueden ver obligadas a ocultar su seropositividad porque justamente saben que eso representa un riesgo para no ser contratadas, así que es: cierto, pero por otro lado encuentro algo trivial hacerlo de esa forma $\S$

\section{(18) LAU1A, Embauche}

Mon $11-$ moi je trouve trivial de de de ouais tout de suite faire passer un test comme ça au \# personnel pour dire "alors on vous fait pas confiance dès le départ et puis on va vérifier", d'un autre côté c'est clair que: ben voilà \# c'est vrai que certaines personnes peuvent être amenées à ca'cher leur séropositivité parce que justement elles savent que elles ont encore un risque de 'pas être engagées, donc c'est: vrai, mais d'un autre côté je trouve que c'est c'est un peu trivial quoi de s'y prendre comme ça§

Como lo hemos visto, Monique introduce un movimiento contra-argumentativo en su propio discurso ("por un lado está claro que: pues sí \# es verdad que ciertas personas se pueden ver obligadas a ocultar su seropositividad [...])". Este movimiento, que se constituye como típico de la anticipación de la comprensión responsiva de su interlocutor, puede ser visto, igualmente, como la expresión de dos posiciones que la locutora podría asumir...

De la misma manera, las modalizaciones y los comentarios metaenunciativos pueden sustentar su razón en el posicionamiento del sujeto en el debate. Este es el caso de Ana, cuyos movimientos discursivos conllevan la reafirmación de una posición puesta en duda por su interlocutor: 


\section{(19) LAU1A, Pareja}

JOE - SÍ PERO < risa de los demás>, porque ya cuando tú dices que la relación de confianza está rota, sí y no, + en el sentido que eres tú la que juzgas el hecho de que la relación de confianza esté rota $\S$ pero pienso $\S$

(...)

ANA 34 -bueno, soy de pronto algo, algo dura porque < risas en el transfondo > pero bueno, asumo que una pareja-, pues si, yo creo que debe haber confianza en una pareja, y pues a mí, me parece que por los comentarios hechos aquí, se trata de una mujer que para empezar no ha asumido sus responsabilidades.

\section{(19) LAU1A, Couple}

JOE $48 \quad$-OUI MAIS <rires des autres>, parce que déjà quand tu dis la relation de confiance est rompue, oui et non, + dans le sens que c'est toi qui porte un jugement sur le fait que la relation de confiance est rompue §mais je pense§

(...)

ANA 34 -bon moi je je suis peut-être un peu un peu dure parce que- < rires en arrière

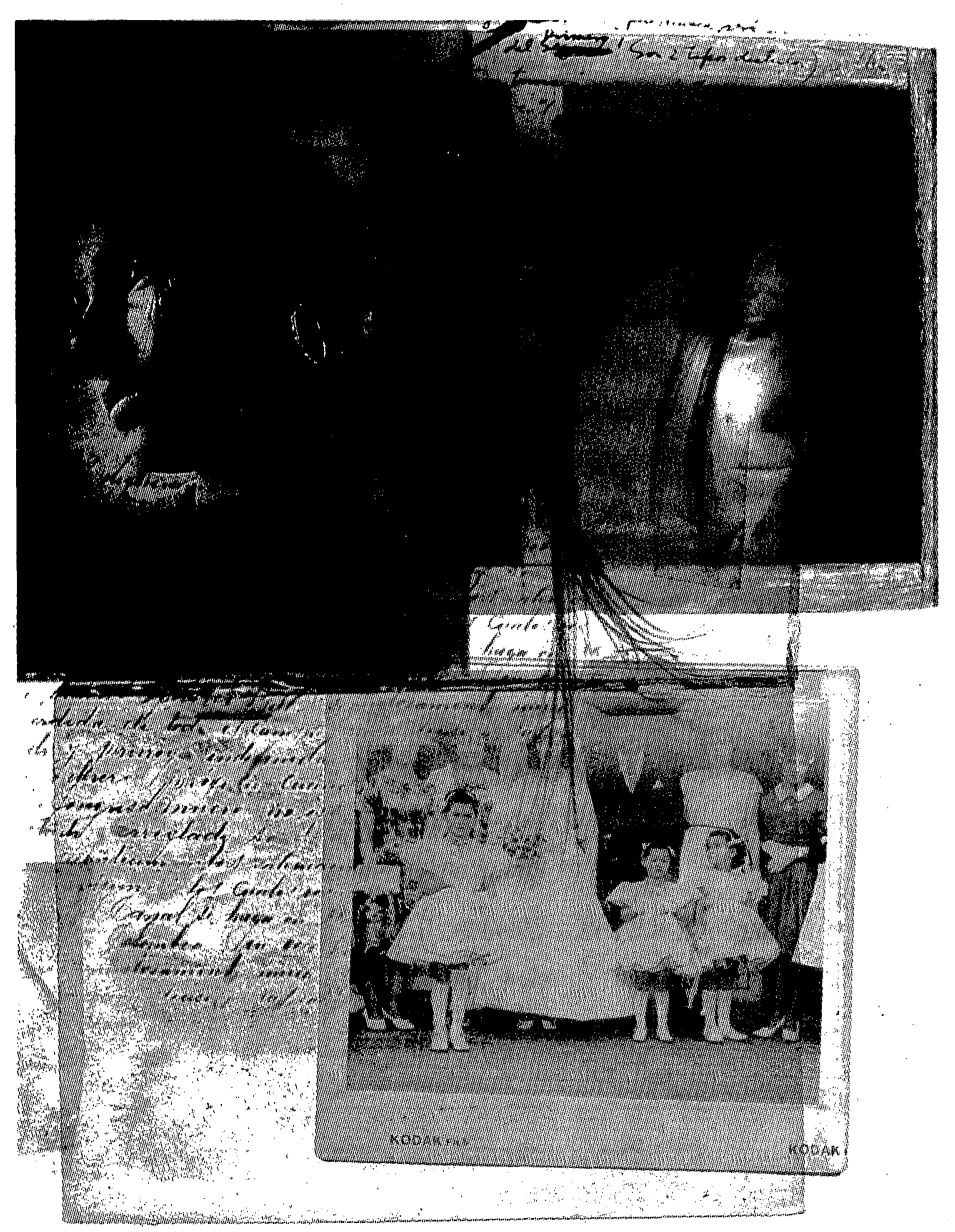

fond $>$ mais bon je pars du fait qu'un couple-, et pis bon moi je pense qu'il doit avoir confiance entre le couple, et pis moi il me semble que c'est déjà par les les remarques ici, c'est déjà une femme qu'a déjà pas pris ses responsabilités,

"Soy de pronto algo, algo dura" está doblemente orientado: se trata de un comentario que prepara la recepción de su propio discurso y, al mismo tiempo, lo marca con un posicionamiento en relación con el reproche de Joël. Desde este punto de vista, parece difícil considerar - como lo hace Vion (1998a y 1998b) - tales formas como la expresión de una unicidad enunciativa. Son, por el contrario, generalmente, movimientos responsivos.

Tomemos un nuevo ejemplo:

\section{(20)LAU1A, Contrato}

ANI 39 -los médicos de los que hablaba, ¿usted cree que serían un grupo en riesgo, desde el punto de vista de lo que Ud. dice?

JOE 26 -yo pienso, no pienso realmente, porque pienso que es más bien- el riesgo del médico está en adquirirlo más que en transmitirlo $<$ riendo> por decirlo así\# $\S$ en contagiarse $\S$

ANI $40 \quad$-sí

ANI $41-\S$ en contagiarse $\S$

JOE 27 -más en contagiarse que en transmitirlo, \# eh en el sentido en que el médico va a verse confrontado con gente que tienen sí, sí, que tienen sida y pues es necesario que tome todas las medidas para protegerse \#, de manera eficaz, contra este tipo de enfermedad.

\section{(20) LAU1A, Embauche}

ANI 39 -les médecins dont vous parliez, vous vous pensez que ce serait un groupe à risque alors du point de vue de ce que vous dites?

JOE $26 \quad-$ moi je pense je pense pas vraiment, parce que je pense c'est plutôt- le risque du médecin c'est plutôt de l'avoir que de le 'donner <en riant> si je puis dire\# de \$l'attraper§
ANI 40 -ouais
ANI 41 —§de l'attraper§ 
JOE 27 -de l'attraper que de le donner, \# euh dans le sens où il va être confronté à des gens qui ont euh ont le si- le si- qui ont le sida et pis qu'il faut qu'il prenne toutes les mesures pour se protéger \#, efficacement, de ce genre de maladie.

Consideremos la aserción de Joël, en 26 y 27 ("el riesgo del médico está en adquirirlo más que en transmitirlo [...] más en contagiarse, que en transmitirlo"). Esta aserción se ve modalizada por pienso y por más bien. El análisis podría detenerse aquí, como lo hace la mayoría de los estudios sobre la modalización. Pero, si retrocedemos en el diálogo, vemos que pienso se opone también al enunciado de la animadora: "los médicos de los que hablaba, usted cree que sería un grupo en riesgo". La animadora le atribuye a Joël un pensamiento y Joël modaliza también en relación con este pensamiento atribuido. De esta forma, Joël hace dos cosas con este enunciado, modaliza su aserción y se posiciona en relación con la pregunta de la animadora y sus implicaciones.

Podríamos considerar, por lo tanto, que la modalización no está necesariamente autoorientada sino que también puede responder a un enunciado anterior, y ser una herramienta de negociación de las representaciones recíprocas que se construyen en el diálogo.

Además de esto, el recurso a la modalización y a los comentarios metaenunciativos está ampliamente determinado por la posición de los locutores en una situación de discusión como ésta y, por eso, no aparecen en cualquier momento en el discurso.

\section{(21) $\mathbb{L} \mathbb{A} U 1 \mathbb{A}$, Contrato}

ANA 23 -sí, claro, bueno yo diría verdaderamente eh en el caso en que se sabe exactamente, en las situaciones donde hay altos riesgos, pienso que es de todas formas mejor saberlo, pues, no sé, me parece: por honestidad con la paciente también \# porque quiero decir, si uno se va a hacer curar se tiene confianza \# y pues, pero es verdad que hay que hacer la distinción entre los diferentes- diferentes campos, porque creo que hay casos donde quiero decir, medicina general no hay problema, pero hay casos + sí, operación quirúrgica: eh no sé, me haría más preguntas, YO por ejemplo, si fuera paciente me gustaría que me lo dijeran \#<muy suavemente> no sé.

\section{(21) $\mathbb{L} \mathbb{A} 1 \mathbb{A}, \mathbb{E m b a u c h e}$}

ANA 23 -ouais tout à fait, bon moi je dirais vraiment euh dans les cas où on sait exactement dans les situations où il $\mathrm{y}$ a des hauts risques, je pense que c'est quand même bon de le savoir enfin je sais pas, il me semble: par honnêteté vis-à-vis de la patiente aussi \# parce que je veux dire si on va se faire soigner on a confiance \# et pis mais c'est vrai qu'il faut faire la distinction entre les différents- différents domaines, parce que je pense qu'il y a des domaines où on je veux dire médecin généraliste on risque rien, mais des des cas + oui opération chirurgie: euh je sais pas je me poserais déjà plus de questions, MOI par exemple si j'étais patiente je voudrais le savoir \#<très doucement $>$ je sais pas.

La existencia del dilema entre proteger al individuo (que solicita empleo) o proteger al público (en este caso los eventuales pacientes de un hospital) se expresa por una gran cantidad de marcas de modalización y de expresión metadiscursivas. Éstas acompañan el razonamiento de los locutores y les permiten avanzar posiciones sin comprometerse completamente. De esta forma, una locutora que no modaliza mucho cuando defiende el respeto al secreto profesional en la viñeta contra

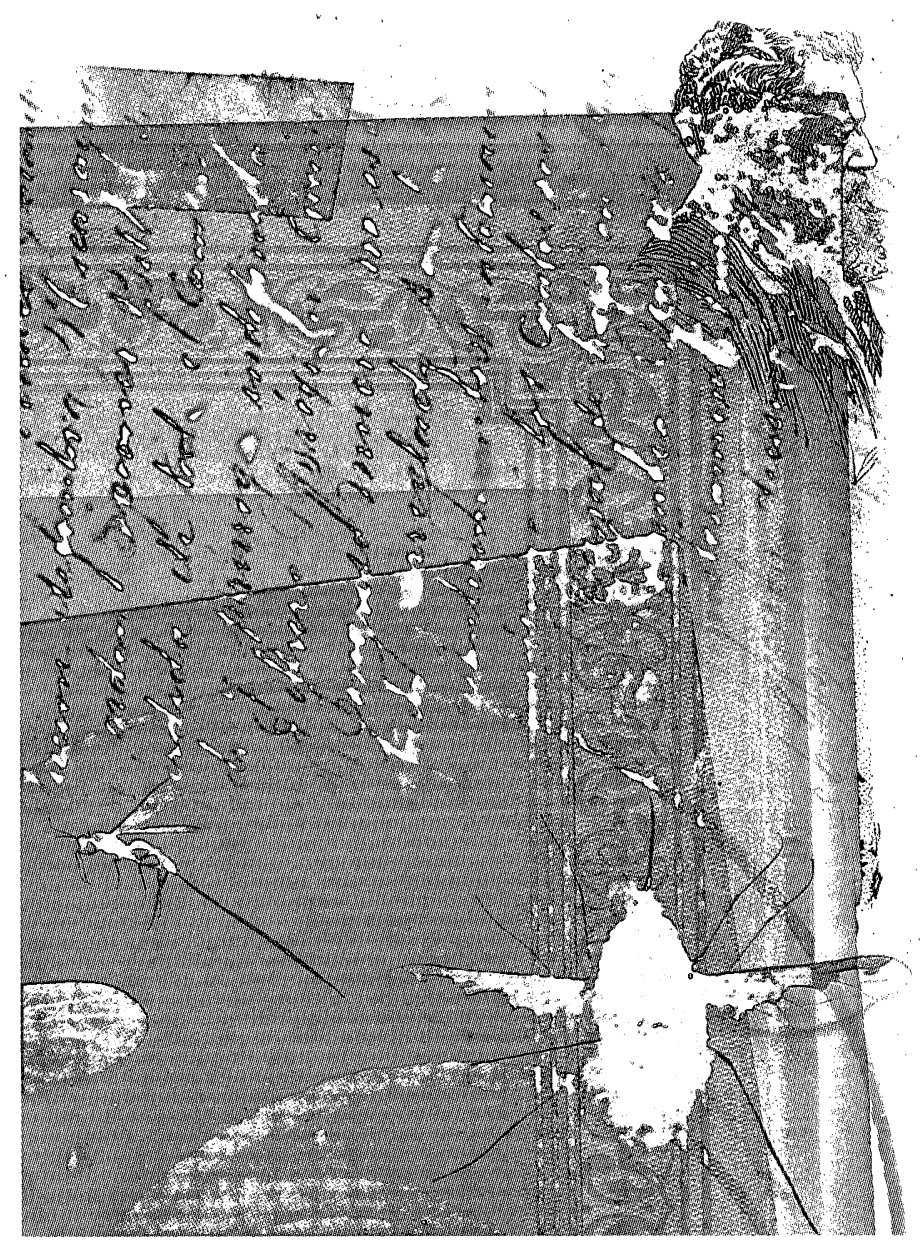


to, se pone a modalizar y modular su discurso cuando se encuentra en la posición opuesta en la discusión de la viñeta pareja:

\section{(22) $\mathbb{L A U} 1 \mathbb{A}$, Pareja}

MON -bueno me parece que es obvio, hay que ponerle algunos bemoles eh, pero eh, en este caso, en la medida en que el médico eh, como dicen ahí, estableció una relación de confianza con Juan y con Paulina, pienso que: sí pues, los riesgos son demasiado grandes, como dices pueden pasar dos meses, o más, \# para eh para eh para esconderle ese diagnóstico a, a Juan.

\section{(22) IAUU1A, Couple}

MON -bon je trouve que c'est c'est sûr quoi les bémols il faut en mettre hein, mais euh dans le cas présent dans la mesure où le médecin euh, comme c'est dit là, a établi une relation de confiance avec Jean autant qu'avec Pauline, je pense que: ouais les risques sont trop grands, comme tu dis aussi deux mois peuvent s'écouler, voire plus, \# pour euh pour euh cacher cette ce diagnostic à à Jean.

Lo que está en juego en este ejemplo es, probablemente, la forma en que el autodialogismo manifiesta una tensión interna, no desplegada, entre diferentes posiciones. El sujeto trae consigo diferentes voces que corresponden a igual número de posiciones en relación con sus interlocutores, pero, también, en relación con una doxa y a expectativas compartidas. Tenemos aquí, por lo tanto, otro tipo de continuum entre dialogismo inmediato y dialogismo a distancia con la doxa y el interdiscurso.

\section{ALGUNAS PALABRAS PARA CONCLUIR}

La observación de estos discursos nos permite ver hasta qué punto interviene el dialogismo en todos los niveles de la constitución del discurso. Pero estos diálogos muestran, igualmente, que no se puede funcionar con oposiciones tajantes: trabajamos más bien con diversas combinaciones de diferentes continuums. Cada movimiento discursivo debería poder situarse en algún lugar, sobre los siguientes ejes (de una lista que está lejos de ser definitiva), definidos por sus polos:

- Dialogismo a distancia vs dialogismo inmediato, y - entre los dos- los diferentes tipos de intertextualidad.
- Autodialogismo vs heterodialogismo, y -entre los dos- los diferentes tipos de heterogeneidad enunciativa.

- Dialogar con otro (ausente o presente) vs convocar diferentes voces (Bres, 1998) ${ }^{15}$ (aquí, en nuestro caso, la puesta en escena de discursos ficticios).

- El material del dialogismo: palabras, contenidos, estilos, géneros, códigos...

- Discurso oculto del otro vs discurso citado del otro $\mathrm{y}$-entre los dos- las diférentes modalidades de representación del discurso.

- Discurso comprobado del otro, cuyo origen es localizable $v s$ discurso ficticio, y -entre los dosel discurso atribuido o proyectado (Authier-Revuz, 1995).

- Enunciado como respuesta vs enunciado como anticipación de su comprensión responsiva.

Muy a menudo, el trabajo sobre el diálogo efectivo ha sido considerado como carente de pertinencia, debido a las dificultades que acarrea y porque se ha privilegiado los estudios del dialogismo a distancia. Y, también, porque se considera que lo que se puede observar en el diálogo efectivo corresponde más bien a las propiedades generales de la organización y de la coherencia de los discursos (Moirand, 2003). Por ejemplo, como lo acabamos de demostrar, desde el momento en que nos interesamos por la imbricación extrema de las palabras de los interlocutores, lindamos con los fenómenos de cohesión y continuidad. Pero, me parece que el razonamiento debe hacerse en sentido inverso; y un corpus como éste lo muestra bien (Salazar et al., 2004) ${ }^{16}$ : se trata, en realidad, de fenómenos que son en un principio dialógicos antes de ser monológicos...

De la misma forma, en concordancia con la posición bajtiniana que considera que hay que partir de los movimientos discursivos para ir hacia lás unidades (y no al contrario), la observación de los movimientos en la dinámica dialógica del diálogo permite también otra comprensión de los fenómenos gramaticales. Sería necesario, ahora, poder

\footnotetext{
${ }^{15}$ Como la polifonía de la novela.

${ }^{16} \mathrm{Y}$ los datos de la adquisición del niño tenderían a confirmar esta perspectiva.
} 
ubicar el estudio de las marcas lingüísticas de dialogismo en el contexto de estas diferentes facetas. En todo caso, teniendo en mente un continuum entre fenómenos gramaticales integrados en el enunciado y movimientos que son antes que nada discursivos y, sobretodo, dialógicos.

Finalmente, se ha podido oír aquí o allá que si el dialogismo es un hecho constitutivo del lenguaje, se encuentra, por lo tanto, en todos los ámbitos y por eso pierde su especificidad y su poder explicativo... pero, se corre igualmente el riesgo opuesto. Al querer circunscribir el alcance del dialogismo a unos cuantos fenómenos lingüísticos o discursivos, se puede olvidar su carácter fundamental. $\mathrm{Al}$ contrario, sólo el reconocimiento de las profundas consecuencias de este fenómeno puede servir de base para nuestra concepción de la lengua, de la elaboración del discurso, al igual que de los procesos psico- y sociolingüísticos.

\section{BIBLIOGRAFÍA}

AUTHIER-Revuz, J., (1995), Ces mots qui ne vont pas de so: boucles réflexives et non-coïncidences $d u$ dire, París, 2 vol., Larousse.

BAJTín, M., (1986), Problemas de la poética de Dos-toïevsky, traducción de Tatiana Bubnova, México, Fondo de Cultura Económica.

- y V. N. Voloshinov, (1992), El marxismo y la filosofía del lenguaje, traducción de Tatiana Bubnova, Madrid, Alianza Editorial.

-, (1989), Teoría y estética de la novela, traducción de Helena S. Krúkova y Vicente Cazcarra, Madrid, Taurus.

-, (1982), Estética de la creación verbal, traducción de Tatiana Bubnova, México, Siglo XXI Editores.

BALLY, C., (1942), "Syntaxe de la modalité explicite", en: Cahiers Ferdinand de Saussure, (2), 3-13.

BRES, J., (1998), "Entendre des voix de quelques marqueurs dialogiques en français", en! J. Bres, R. Delamotte-Legrand, F. Madray-Lesigne y P. Siblot, (eds.), L'autre en discours, Montpellier et Rouen, Praxiling et Dyalang.

-, (1999), "Vous les entendez? Analyse du discours et dialogisme", Modèles linguistiques, XX, 2: 71-86.

- y B. Vérine, (2002), "Le bruissement des voix dans le discours: dialogisme et discours rapporté", Faits de langues, No. 19: 159-169.

DUCRot, O., et. al., (1980), Les mots du discours, París, Minuit.

—, (1984), Le dire et le dit, París, Minuit.

—, (1986), El decir y lo dicho. Polifonía de la énunciación, Barcelona, Paidós.

FouCAUlt, M., (1969), L’archéologie du sávoir, París, Gallimard.

—, (1970), La arqueología del saber, México, Siglo XXI.
FraNÇOIS, F., (1984), "Problèmes et esquisse 'méthodologique", en: F. François, C. Hudelot y E. SabeauJouannet, Conduites linguistiques chez le jeune enfant, París, PUF : 13-116

HAILLET, P.P., (1998), "Quand un énoncé en cache un autre: le conditionnel et les relatives appositives", en: J. Bres, R. Delamotte-Legrand, F. Madray-Lesigne y P. Siblot (eds.), L'autre en discours, Montpellier et Rouen, Praxiling et Dyalang : 213-238.

-, (2002), Le conditionnel en français : une approche polyphonique, París, Ophrys.

LINELL, P., (1998), Approaching dialogue. Talk, interac-tion and contexts in dialogical perspectives, Amsterdam, John Benjamins.

-, (2003), What's dialogism? Aspects and elements of a dialogical approach to laguage, communication and cognition, [documento de trabajo].

MARVOKÁ, I., (2003a), "Focus groups", en: S. Moscovici, y F. Buschini (eds.), Les méthodes des sciences humaines, París, Presses Universitaires de France.

-, (2003b), Dialogicallity and social representations. The dynamics of mind, Cambridge, Cambridge University Press.

MOIRAND, S., (2002), “Dialogisme”, en: P. Charaudeau y D. Maingueneau (eds.), Dictionnaire d'analyse du discours, París, Seuil.

—, (2003), "Le dialogisme à l'épreuve de la circulation des discours sur la science dans les médias", [conférence au Séminaire du LEAPLE], enero.

PecheuX, M., (1975), Les vérités de la Palice, París, Maspéro.

ROULET, E. et. al., (1985), Larticulation du discours en français contemporain, Berne, Peter Lang.

SALAZAR Orvig, A., et al., (2004), "Emergence des marqueurs anaphoriques avant 3 ans: le cas des pronoms de troisième personne", en: Calap, n. 24, s. p.

SALAZAR Orvig, A. y M. Grossen, (2004a), "Représentations sociales et analyse de discours produit dans des focus groups: un point de vue dialogique", Bulletin de Psychologie, tome 57, No. 3, pp. 263-272.

—, (2004b), "Hétérogènéité dans l'espace discursif: Approche dialogique des représentations sociales", Actes $d u$ colloque de sociolinguistique "Variation, catégorisations et pratiques discursives", París, Université de Paris 3.

ToDoRov, T., (1981), Mikhaïl Bakhtine, le principe dialogique, París, Seuil.

VION, R., (1992), La communication verbale. Analyse des interactions, París, Hachette.

-, (1998a), "De l'instabilité des positionnements énonciatifs dans le discours", en: J. Verschueren (ed.), Pragmatics in 1998: Selected papers from the $6^{\text {th }}$ interna-tional conference, Anvers, International Pragmatics Association.

—, (1998b), "Le sujet en linguistique", en: R. Vion (ed.), Les sujets et leurs discours, Aix en Provence, Publication de l'Université de Provence.

-, (2001), "Modalités, modalisations et activités langagières", Marges linguistiques, n. 2. 